\title{
Bioactive Compounds, Antioxidant Activities, and Health Beneficial Effects of Selected Commercial Berry Fruits: A Review
}

\author{
Boris V. Nemzer ${ }^{1,2}$, Diganta Kalita ${ }^{1}$, Alexander Y. Yashin ${ }^{3} \&$ Yakov I. Yashin ${ }^{3}$ \\ ${ }^{1}$ Department of Research \& Development, VDF FutureCeuticals, Inc., Momence, IL 60954, USA \\ ${ }^{2}$ Department of Food Science and Human Nutrition, University of Illinois at Urbana-Champaign, Urbana, IL \\ 61801, USA \\ ${ }^{3}$ International Analytical Center of Zelinsky, Institute of Organic Chemistry, Moscow 119991, Russia \\ Correspondence: Boris V. Nemzer, Department of Research \& Development, VDF FutureCeuticals, Inc., \\ Momence, IL 60954, USA. Tel: 1-815-507-1427. E-mail: bnemzer@ futureceuticals.com
}

Received: June 18, 2020

doi:10.5539/jfr.v9n5p78

\author{
Accepted: August 20, $2020 \quad$ Online Published: September 10, 2020 \\ URL: https://doi.org/10.5539/jfr.v9n5p78
}

\begin{abstract}
Epidemiological studies have provided the evidence that regular consumption of fruits and vegetables reduce the risk of pathological condition such as cardiovascular disease, cancer, inflammation, and aging. Among fruits, berries are considered as superfruits due to their highly packed phytochemicals comprising phenolic acids, flavonoids viz. flavonols, flavanols, and anthocyanins. These bioactive compounds are associated with significant antioxidant, antidiabetic, antiinflammation, and anticancer properties. This review highlights the basic information and interesting findings of some selected commercial berries with their phytochemical composition, antioxidant properties, and potential health benefits to human.
\end{abstract}

Keywords: berries, polyphenols, antioxidant activity, antidiabetic and anticancer properties, nutrition

\section{Introduction}

Free radicals are reactive oxygen or nitrogen molecule that damage cellular biomolecules viz. protein, nucleic acid, lipids membranes and results in various pathological condition such as cardiovascular disease, cancer, inflammation, and aging (Sun, 1990; Valko, Leibfritz, Jan, Cronin, Mazur, \& Telser, 2007; Phaniendra, Jestadi, \& Periyasamy, 2015). Antioxidants are molecule that scavenge or inhibit the actions of reactions of free radical to protect the cells and tissues (Uttara, Singh, Zamboni, \& Mahajan, 2009). Several epidemiologic studies demonstrated that consumption of fruits and vegetables could lower these chronic pathologies including obesity, inflammation, cardiovascular diseases, and cancer due to their strong antioxidant activities (Kristo, Klimis-Zacas, \& Sikalidis, 2016; Kalemba-Drożdż, Cierniak, \& Cichoń, 2020). Among fruits, berries are important part of the human diet for many centuries and are receiving considerable attention continuously all over the world due to their beneficial effects to the human health and nutrition (Bravo, 1998; Nile\& Park, 2014, Cianciosi, Simal-Gándara, \& Forbes-Hernández, 2019).

Berries are considered as superfruits due to their high packed phytochemicals, dietary fibers, vitamins, and minerals. Berries polyphenolic compounds composed of diverse group of compounds which include phenolic acids, flavonoids viz., flavonols, flavanols, and anthocyanins. Phenolic acids are the derivatives of benzoic acid and cinnamic acid and consist of an aromatic ring structure with hydroxyl group. However, hydroxy derivatives of cinnamic acid are much more abundant than hydroxybenzoic acid among berries. Among flavonoids berries phenolic compounds include anthocyanins, flavanols, flavonols, and proanthocyanidins. These groups differ each other in the spatial positions and numbers of hydroxyl and alkyl groups on the basic chemical structure. Anthocyanins are the most abundant among flavonoids and are responsible for the color of the fruits. In their structure anthocyanins are glycosylated with glucose, galactose, rhamnose, xylose, or arabinose are attached to the aglycone called anthocyanidins mainly cyanidin, pelarogonidin, malvidin, petunidin, delphinidin, and peonidin. Usually the sugar components of anthocyanins are connected to the anthocyanidin skeleton via the C3 hydroxyl group in ring $\mathrm{C}$ of the anthocyanin.

Due to the presence of these polyphenolic compounds berries and their extracts exhibit several health benefits such as retarding inflammation, lowering cardiovascular diseases, or protect to lower the risk of various cancers, 
and antioxidant activities (Heinonen, Meyer, \& Frankel, 1998; Seeram, Adams, Zhang, Lee, Sand, Scheuller, \& Heber, 2006; Pan, Skaer, Yu, Hui, Zhao, Ren, Oshima \& Wang, 2017; Reboredo-Rodr'1guez, 2018; Pan et al., 2018). However, the contents of polyphenols and nutrients of berries are highly dependent on genotypes, environments, and the cultivation techniques. In addition to these, various agronomic factors such as pre and postharvest practices, maturity at harvest, storage, and processing operations plays crucial role in the quality and levels of phytochemicals in berries. Interestingly among these factors the genotype plays most significant role which regulates the content of nutrients and phytochemicals and influence health beneficial activities. In an important study Halvorsen et al., (2006) evaluated 1120 food samples listed in USDA for antioxidant content and found that blueberries, strawberries, cranberries and their juice product occupied top position in the first 50 antioxidant rich foods (Halvorsen et al., 2006). Large body of literature is available with studies of berries' health benefits to humans. Recently Yeung, et al., (2019) concluded that berries which were mentioned at the 100 top cited research articles dealing with anticancer and antioxidant activities were strawberry, blueberry, cranberry, raspberry, blackberry, billberry, and grape berry. However, at the current time in addition to these commonly cultivated berries some other native berry fruits viz, sea buckthorn, acai, maqui, viburnum, and elder berries are gaining remarkable attention worldwide due to their rich source of antioxidants. Due to the increasing demand of antioxidant rich berries, continuous research on the identification of phytochemicals and their health benefits of these berries have been carried out. However, a very few review and research articles are seen covering most of the top commercial berries. In this review article we provide an overview of polyphenolic composition of selected top commercial berries and their health beneficial properties.

\section{Commercial Berries}

Berries are available with distinctive skin and flesh colors such as red, blue, or purple. They are highly perishable fruits. Some of the top commercial varieties of berries include members of genera: Fragaria (strawberry), Vaccinium (blueberry, cranberry, bilberry), Prunus (cherries), Hippophae (sea buckthorn), Rubus (raspberries), Euterepe (açaí berry), Aristotelia (Maqui berry), and Sambucus (elderberry, red elderberry).

\subsection{Strawberries}

\subsubsection{Source}

Strawberry fruits belong to the family of Rosaceae and genus Fragaria are globally cultivated for their popularity due to distinctive aroma, bright red color, and juicy texture. The plant is widely cultivated worldwide, intensively in Europe, USA, and China. The USA is the world leading producer of strawberries after Turkey and Spain. The US strawberry industry has significantly rising as per person consumption increasing because of the high consumer acceptance for its sensory attributes.

\subsubsection{Composition}

Vitamin $\mathrm{C}$ is one of the major nutrients available in strawberries. Other vitamins such as thiamine, riboflavin, niacin, and vitamins A, E, K, and B6 including carotenoids are also available in strawberries (Rothwell et al., 2013, Fierascu, Temocico, Fierascu, Ortan, \& Babeanu, 2020). However, depending on the varieties, geographic, and agronomic condition these levels vary among them (Aaby, Mazur, Nes, \& Skrede, 2012; Nowicka, Kucharska, Sokół- $\biguplus_{c}$ etowska, \& Fecka, 2019, Akimov, et al., 2019). The major polyphenolic compounds in strawberries are flavonol, flavanol, anthocyanins, and phenolic acids (Kähkönen, Hopia, \& Heinonen, 2001; Aaby, Skrede, \& Wrolstad, 2005; Giampieri, et al., 2020), (Table 1). Moreover, the major polyphenolic compounds in strawberries are anthocyanins and they are responsible for the color of the fruits. The major anthocyanins in strawberries are derivatives of pelargonidin and cyanidin with glycosides or acylated forms such as pelargonidin 3-glucoside, cyanidin 3-glucoside, cyanidin 3-rutinoside, pelargonidin 3-galactoside, pelargonidin 3-rutinoside, pelargonidin 3-arabinoside, pelargonidin 3 malylglucoside etc (Lopes-da-Silva, de Pascual-Teresa, Rivas-Gonzalo, \& Santuos-Buelga, 2002; Giampieri, et al., 2020). Quercetin, kaempferol, fisetin, and their glycoside were found to be as major flavonols in strawberries. Among flavanols catechin, proanthocyanidin B1, proanthocyanidin trimer, proanthocyanidin B3 were reported to be major ones. Phenolic acids such as 4-coumaric acid, p-hydroxybenzoic acid, ferulic acid, vanillic acid, sinapic acid were found to be in significant level in strawberries. Storage and processing greatly influence the quality and levels of phenolic and anthocyanin compounds of strawberries. In the processed products such as jams, jellies, puree, and juices the levels of phenolic compounds decrease relative to the fresh strawberries (Álvarez-Fernández, Hornedo-Ortega, Cerezo, Troncoso, García-Parrilla, 2014; Méndez-Lagunas, Rodríguez-Ramírez, Cruz-Gracida, Sandoval-Torres, \& Barriada-Bernal, 2017). The color and composition of anthocyanins are affected by $\mathrm{pH}$. During storage lower $\mathrm{pH}(2.5)$ were found to be better to preserve its polyphenols. 
Table 1. Major phenolic compounds in selected commercial berries

\begin{tabular}{|c|c|c|c|c|}
\hline Berries & Flavonol & Phenolic acid & Anthocyanin & Flavanol \\
\hline \multirow[t]{16}{*}{ Strawberries } & Kaempferol & 4-Hydroxybenzoic acid & Cyanidin & $(+)$-Catechin \\
\hline & 3-O-glucoside & 4-O-glucoside & & \\
\hline & Kaempferol & 5-O-Galloylquinic acid & Cyanidin & (+)-Gallocatechin \\
\hline & 3-O-glucuronide & & 3-O-(6"-succinyl-glucoside) & \\
\hline & $\begin{array}{l}\text { Quercetin } \\
\text { 3-O-glucuronide }\end{array}$ & Ellagic acid glucoside & Pelargonidin & (-)-Epicatechin 3-O-gallate \\
\hline & Kaempferol & 5-Caffeoylquinic acid & $\begin{array}{l}\text { Pelargonidin } \\
\text { 3-O-(6"-malonyl-glucoside) }\end{array}$ & (-)-Epigallocatechin \\
\hline & Myricetin & Caffeoyl glucose & Pelargonidin 3-O-arabinoside & Procyanidin dimer B1 \\
\hline & Quercetin & Cinnamic acid & Pelargonidin 3-O-glucoside & Procyanidin dimer B2 \\
\hline & & Feruloyl glucose & Pelargonidin 3-O-rutinoside & Procyanidin dimer B3 \\
\hline & & p-Coumaric acid & pelargonidin 3 malylglucoside & Procyanidin dimer B4 \\
\hline & & p-Coumaric & & Procyanidin trimer \\
\hline & & 4-O-glucoside & & \\
\hline & & p-Coumaroyl glucose & & \\
\hline & & Vanillic acid & & \\
\hline & & Protocatechuic acid & & \\
\hline & & Sinapic acid & & \\
\hline \multirow[t]{47}{*}{ Blueberries } & Kaempferol & 4-Hydroxybenzoic acid & Cyanidin & \\
\hline & & & 3-O-(6"-acetyl-galactoside) & \\
\hline & Myricetin & Ellagic acid & Cyanidin & \\
\hline & & & 3-O-(6"-acetyl-glucoside) & \\
\hline & Quercetin & Gallic acid & Cyanidin 3-O-arabinoside & \\
\hline & Kaempferol & Caffeic acid & Cyanidin 3-O-galactoside & \\
\hline & 3-O-glucoside & & & \\
\hline & Myricetin & Ferulic acid & Cyanidin 3-O-glucoside & \\
\hline & 3-O-arabinoside & & & \\
\hline & Myricetin & p-Coumaric acid & Delphinidin 3-O-(6"-acetyl-gala & toside) \\
\hline & 3-O-rhamnoside & & & \\
\hline & Quercetin & 5-Caffeoylquinic acid & Delphinidin 3-O-(6"-acetyl-gluc & side) \\
\hline & 3-O-acetyl-rhamnoside & & & \\
\hline & Quercetin & & Delphinidin 3-O-arabinoside & \\
\hline & 3-O-arabinoside & & & \\
\hline & Quercetin & Syringic acid & Delphinidin 3-O-galactoside & \\
\hline & 3-O-galactoside & & & \\
\hline & Quercetin 3-O-glucoside & Vanillic acid & Delphinidin 3-O-glucoside & \\
\hline & Quercetin 3-O-xyloside & 4-Hydroxybenzoic & Malvidin & \\
\hline & & 4-O-glucoside & 3-O-(6"-acetyl-galactoside) & \\
\hline & & Gallic acid 4-O-glucoside & Malvidin & \\
\hline & & & 3-O-(6"-acetyl-glucoside) & \\
\hline & & Protocatechuic $\quad$ acid & Malvidin 3-O-arabinoside & \\
\hline & & 4-O-glucoside & & \\
\hline & & 3-Caffeoylquinic acid & Malvidin 3-O-galactoside & \\
\hline & & 4-Caffeoylquinic acid & Malvidin 3-O-glucoside & \\
\hline & & 5-Caffeoylquinic acid & Peonidin & \\
\hline & & & 3-O-(6"-acetyl-galactoside) & \\
\hline & & 5-Feruloylquinic acid & Peonidin & \\
\hline & & & 3-O-(6"-acetyl-glucoside) & \\
\hline & & 5-p-Coumaroylquinic acid & Peonidin 3-O-galactoside & \\
\hline & & Caffeic acid 4-O-glucoside & Peonidin 3-O-glucoside & \\
\hline & & Ferulic acid 4-O-glucoside & Petunidin 3-O-(6"-acetyl-galact & side) \\
\hline & & p-Coumaric acid & Petunidin & \\
\hline & & 4-O-glucoside & 3-O-(6"-acetyl-glucoside) & \\
\hline & & & Petunidin 3-O-arabinoside & \\
\hline & & & Petunidin 3-O-galactoside & \\
\hline & & & Petunidin 3-O-glucoside & \\
\hline & & & Cyanidin & \\
\hline & & & 3-O-(6"-acetyl-galactoside) & \\
\hline & & & Cyanidin & \\
\hline & & & 3-O-(6"-acetyl-glucoside) & \\
\hline & & & Cyanidin 3-O-arabinoside & \\
\hline & & & Cyanidin 3-O-galactoside & \\
\hline & & & Cyanidin 3-O-glucoside & \\
\hline & & & Delphinidin 3-O-(6"-acetyl-gala & toside) \\
\hline & & & Delphinidin & (-)-Epicatechin \\
\hline
\end{tabular}


3-O-(6"-acetyl-glucoside)

Delphinidin 3-O-arabinoside

Delphinidin 3-O-galactoside

Delphinidin 3-O-glucoside

Malvidin

3-O-(6"-acetyl-galactoside)

Malvidin

3-O-(6"-acetyl-glucoside)

Malvidin 3-O-arabinoside

Malvidin 3-O-galactoside

Malvidin 3-O-glucoside

Peonidin

3-O-(6"-acetyl-galactoside)

Peonidin

3-O-(6"-acetyl-glucoside)

Peonidin 3-O-arabinoside

Peonidin 3-O-galactoside

Peonidin 3-O-glucoside

Petunidin 3-O-(6"-acetyl-galactoside)

Petunidin

3-O-(6"-acetyl-glucoside)

Petunidin 3-O-arabinoside

Petunidin 3-O-galactoside

Petunidin 3-O-glucoside

Peonidin 3-O-glucoside

Petunidin 3-O-(6"-acetyl-galactoside)

Petunidin

3-O-(6"-acetyl-glucoside)

Petunidin 3-O-arabinoside

Petunidin 3-O-galactoside

Petunidin 3-O-glucoside

Caffeic acid

p-Coumaric acid

Chlorogenic acid

Chlorogenic acid

Gallic acid 4-O-glucoside

Cinanamic acid

2,4-Dihydroxybenzoic acid

3-Hydroxybenzoic acid

4-Hydroxybenzoic acid

Benzoic acid

Vanillic acid

Caffeic acid

Cinnamic acid

Ferulic acid

p-Coumaric acid

Sinapic acid

4-Hydroxybenzoic acid

5-Caffeoylquinic acid

Caffeic acid

Ferulic acid

p-Coumaric acid

3-Caffeoylquinic acid

3-Feruloylquinic acid

3-p-Coumaroylquinic acid

-glucos

rcetin 3-rutinoside

Kaempferol 3-rutinoside
4-Caffeoylquinic acid

4-p-Coumaroylquinic acid
Cyanidin 3-O-glucosides

Delphinidin-3-O-glucosides

Peonidin 3-O-glucosides

Petunidin3-O-glucosides

Malvidin 3-O-glucosides

Cyanidin 3-O-galactosides

Cyanidin 3-O-arabinoside

Delphinidin 3-O-arabinoside

Peonidin 3-O-arabinoside

Petunidin3-O-arabinoside

Malvidin s3-O-arabinoside

Cyanidin 3-O-arabinoside

Cyanidin 3-O-galactoside

Cyanidin 3-O-glucoside

Peonidin 3-O-arabinoside

Peonidin 3-O-galactoside

Peonidin 3-O-glucoside

Cyanidin 3-sophoroside

Pelargonidin 3-glucoside

pelargonidin 3-rutinoside
Cyanidin 3-O-glucoside Cyanidin 3-O-rutinoside Pelargonidin 3-O-rutinoside Peonidin 3-O-glucoside Peonidin 3-O-rutinoside
(+)-Catechin

(-)-Epicatechin

(-)-Epicatechin 3-O-gallate

(-)-Epigallocatechin

Procyanidin dimer B1 


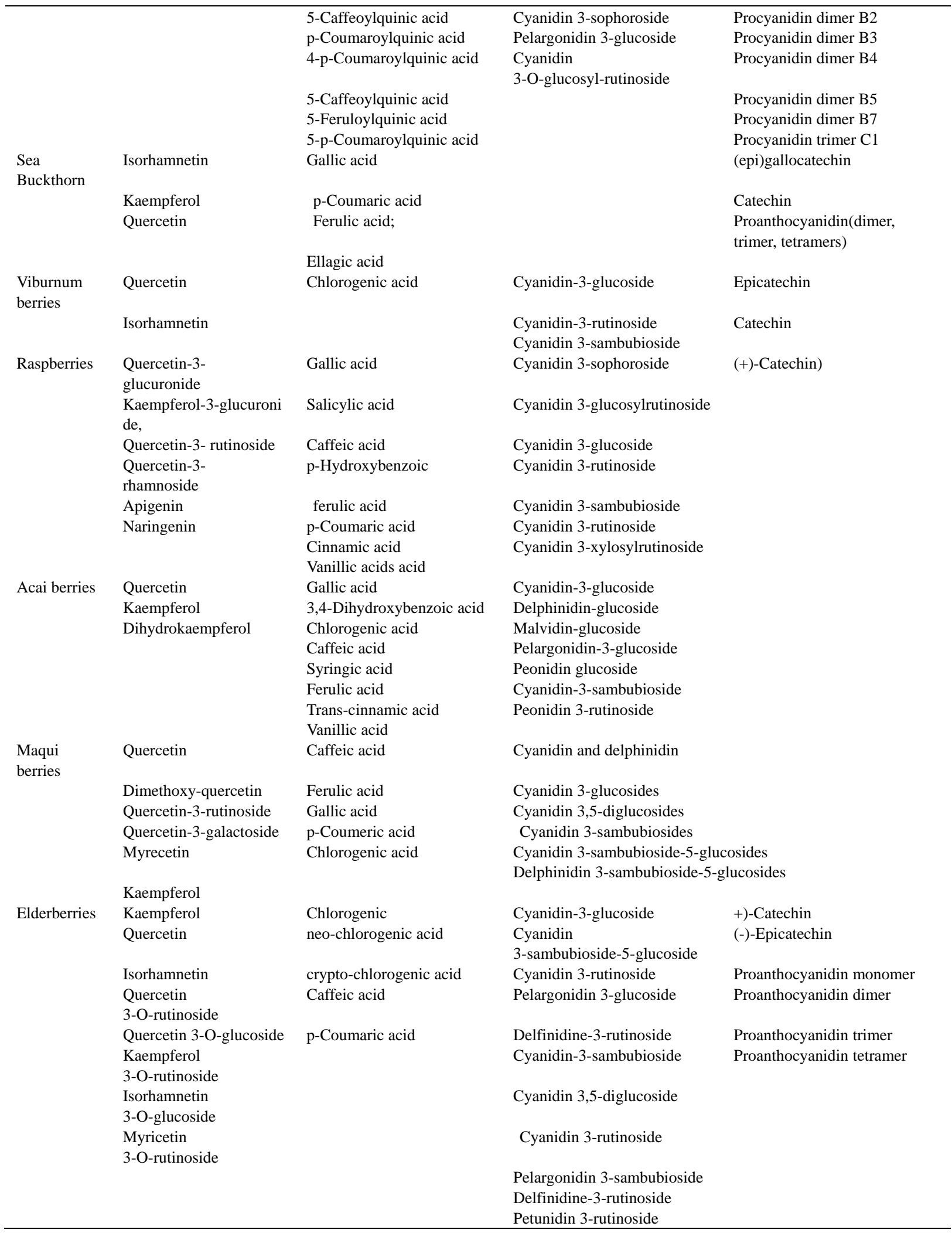

\subsubsection{Health Benefits}

Strawberries shows anti-inflammatory, anti-oxidative, anticancer properties, and other health benefits because of the presence of high levels of flavonoids, anthocyanins, and vitamin C. Large number of studies have been investigated to screen their antioxidant activities adopting DPPH (2,2-diphenyl-1-picrylhydrazyl), ABTS 
(2,2'-azino-bis(3-ethylbenzothiazoline-6-sulfonic acid), peroxyl, and superoxide free radical scavenging assays (Wang \& Lin, 2000; Kähkönen, Hopia, \& Heinonen, 2001, Giampieri, et al., 2012). It has been observed that total phenolic compounds were highly correlated with the radical scavenging activities. Prymont Przyminska et al., (2014) found that daily consumption of strawberries increased the plasma antioxidant activity measured by DPPH assay in healthy subjects (Prymont Przyminska et al., 2014). Strawberries containing anthocyanin crude extracts have been reported to show in vitro antioxidant and anti-proliferative activities in human tumor cell. Ellagic acid and quercetin from strawberries have been shown to promote anti-cancer activity by suppressing the growth of human oral, colon, breast, and prostate cancer cells (Zhang, Seeram, Lee, Feng, \& Heber, 2008; Casto, Knobloch, Galioto,Yu, Accurso, \& Warner, 2013). In vivo and in vitro studies demonstrated that strawberries bioactive compounds reduces intracellular reactive oxygen species concentration, increases the activity of antioxidant enzymes, reduces DNA (Deoxyribonucleic Acid) damage; reduces inflammation, reduces oxidative stress, slows down the aging process, treats stomach ulcers, improves plasma lipid profile, and reduces oxidation of low-density lipoproteins (Giampieri, et al., 2012, Basu, Morris, Nguyen, Betts, Fu, \& Lyons, 2016)). Agarawal et al., (2019) has reported that consumption of strawberries reduces the risk of Alzheimer's dementia (Agarwal, Holland, Wang, Bennett, \& Morris, 2019). Schell et al. (2017) reported that dietary strawberries supplemented to obese adults suffering from osteoarthrities have resulted analgesic and anti-inflammatory effects (Schell et al., 2017). Basu et al., (2016) reported that dietary strawberry selectively increased plasma antioxidant biomarkers in obese adults with elevated lipids (Basu, Morris, Nguyen, Betts, Fu, \& Lyons, 2016).

\subsection{Blueberries}

\subsubsection{Source}

Historically, blueberries have been a popular fruit due to their well-known health and nutritional benefits. Blueberries belongs to family Ericacea and genus Vaccinum. Numerous species (approx. 450) of blueberries are grown wildly or cultivated worldwide. Major commercially available blue berries that are grown across the worldwide are rabbit eye blueberries (Vaccinium ashei), lowbush blueberry (Vaccinium angustifolium A.) and highbush blueberry (Vaccinium corymbosum L.). USA is the largest producer of blue berries in world after Australia and Canada. However various part of the Europe and other countries produce blueberries commercially. Blueberries are highly perishable and therefore blueberries are processed after harvesting. Various postharvest techniques for storage and processing are applied to prolong their shelf lives and preserve quality properties of blueberry.

\subsubsection{Composition}

Blueberries are packed with various nutrients and bioactive active compounds. They are listed top of the superfoods. Blueberries are the richest source of polyphenolic compounds. It also contains several vitamins including vitamin C. Numerous studies have been carried out to screen the level polyphenolic compounds including analysis by chromatographic and mass spectrophotometric analysis. Analysis in the content of total phenolic compounds and total anthocyanins demonstrated that it has several folds differences among the different varieties depending on the geographic location and agricultural practices. Major polyphenolic compounds of blueberries are flavonols (mainly quercetin derivatives), anthocyanins, flavan-3-ols, proanthocyanidins, and phenolic acids (Table 1). Among the phenolic acids of blueberries hydroxycinnamic and hydroxybenzoic acids and their derivatives such as chlorogenic, caffeic, gallic, p-coumaric, ferulic, ellagic, syringic, vanillic acids are common (Kalt \& McDonald, 1996;Kalt, Forney, Martin, \& Prior, 1999, Gu et al., 2004; Rodriguez-Mateos, Cifuentes-Gomez, Tabatabaee, Lecras, Spencer, 2012,; ). Anthocyanins are the major polyphenolic compounds comprising $60 \%$ of total phenolic compounds in blue berries. In a study of 215 phenotypes of blueberries cyanidin-3-glucoside was reported to be the major again among the anthocyanin compounds (Kalt, et al., 2001). In some other studies it was found that malvidin, delphinidin, petunidin, and peonidin are the major components comprising $75 \%$ of all identified anthocyanins (Scibisz \& Mitek, 2007; Routray \& Orsat, 2011).The composition and levels of anthocyanins in blueberries vary with cultivars and varieties. The color of blueberries also varies with the composition of anthocyanins (Routray \& Orsat, 2011). The level of polyphenolic compounds differs with maturity stages of blueberries where ripening stages showed higher level of anthocyanins than the other phenolic compounds. Postharvest condition such as oxygen level, temperature, and light of blueberries impacts the nutritional quality and phenolic contents (Kalt, Forney, Martin, \& Prior, 1999).

\subsubsection{Health Benefits}

Blueberries have tremendous pharmacological properties. Consumption of blueberries help in controlling 
diabetes and its complication such as lowering blood pressure and blood cholesterol (Martineau, et al., 2006; Basu, et al.,2010; Stull, Cash, Johnson, Champagne, \& Cefalu, 2010, McAnulty, Collier, Pike, Thompson, \& McAnulty, 2019). It possesses anti-diabetic properties and help to protect pancreatic $\beta$-cells from glucose-induced oxidative stress (Al-Awwadi, et al., 2005; Martineau, et al., 2006). It has been reported that consumption of blueberry significantly reduced $\mathrm{H}_{2} \mathrm{O}_{2}$-induced DNA damage (Del $\mathrm{Bo}^{\prime}$, et al., 2013). Phytochemicals present in blueberry could inhibit the growth and metastatic potential of breast and colon cancer cells (Adams, Phung, Yee, Seeram, Li, \& Chen, 2010; Schantz, 2010). It was found that pure anthocyanins, such as cyanidin, delphinidin, as well as peonidin 3-glucoside, suppressed growth of human tumor cells and apoptosis of colon and breast cell line. In a recent clinical study comprising 52 US adult veterans reported that consumption of $22 \mathrm{~g}$ freeze-dried blueberries for 8 weeks could beneficially affect cardiometabolic health parameters in men with type 2 diabetes (Stote, et al., 2020). Recently Rodriguez-Daza et al., (2020) revealed the key role of blueberry extract with proanthocynaidins in modulating the gut microbiota and restoring colonic epithelial mucus layer triggering health effects of blueberry polyphenols (Rodriguez-Daza et al., 2020). Moreover Türck, et al., (2020) evaluated the effect of blueberry extract on functional parameters and oxidative stress levels in rat lungs with pulmonary arterial hypertension (PAH) and reported that intervention with blueberry extract mitigated functional PAH outcomes through improvement of the pulmonary redox state (Türck et al., 2020). Tian et al., (2019) reported that cyanidin-3-arabinoside extracted from blueberry as a selective Protein Tyrosine Phosphatase 1B Inhibitor (PTP1B) which is an important target for type 2 diabetes (Tian et al., 2019). PTP1B inhibitors can reduce blood glucose levels by increasing insulin sensitivity. Jielong et al., (2019) reported that extracts of blueberry reduces obesity complications through the regulation of gut microbiota and bile acids via pathways involving FXR(Farensoid X Receptor) and TGR5 (Jielong, Xue, Hongyu, Weidong, Yilin, \& Jicheng, 2019).

\subsection{Bilberries}

\subsubsection{Source}

Bilberry (Vaccinium myrtillus L.) a small dark blue berry belongs to Ericacea family and is native to Europe and North America. Bilberry is also known as European blueberry differs from blueberry relative to Vaccinium corymbosum and Vaccinium angustifolium with their morphology and flesh color. The blue coloration is due to its high content in anthocyanin (Prior et al., 1998). Cultivation of bilberries have been increasing continuously during several years.

\subsubsection{Composition}

Bilberry contains several polyphenolic compounds such as lignin, flavonoids, tannins, and phenolic acids (Bravo, 1998) (Table1). Among flavonoids of bilberries anthocyanins are the major compounds while simple phenolics constitute phenolic acids such as cinnamic acid, gallic acid, caffeic acid, and chlorogenic acid (Puupponen-Pimiä et al., 2001; Taiz \& Zeiger, 2006). The bilberries contain five different anthocyanidins comprising cyanidin, delphinidin, peonidin, petunidin, and malvidin with three sugar moieties viz., 3-O-arabinoside, 3-O-glucosides and 3-O-galactosides (Martinelli, Baj, Bombardelli, 1986).

\subsubsection{Health Benefits}

Due to the presence of anthocyanins as major bioactive compounds in bilberry fruit it exhibits several health-promoting properties (Park, Shin, Seo, Kim, 2007; Schantz, Mohn, Baum, \& Richling, 2010, Pieberger et al., 2011; Kolehmainen et al., 2012). Recently, Arevstrom et al., (2019) in a study involving 50 patients found that bilberry powder supplementation ( $40 \mathrm{~g} /$ day) over eight weeks significantly reduced both total and LDL (low-density lipoprotein) cholesterol compared to baseline (Arevstrom et al., 2019). Karlsen et al., (2010) investigated the effect of bilberry juice on serum and plasma biomarkers of inflammation and antioxidant status in subjects with elevated levels risk factor for cardiovascular disease (CVD) and found that supplementation with bilberry polyphenols modulated the inflammation processes (Karlsen et al., 2010)). Triebel et al., (2012) investigated the influence of bilberry (Vaccinium myrtillus L.) extract containing anthocyanins on pro-inflammatory genes in IFN- $\gamma / \mathrm{IL}-1 \beta / \mathrm{TNF}-\alpha$ stimulated human colon epithelial cells (T84) and demonstrated that anti-inflammatory activity mostly depends on the aglycon structure and the sugar moiety of the billberry anthocyanin (Triebel, Trieu, \& Richling, 2012). Roth et al., (2014) reported that bilberry-derived anthocyanins reduced IFN- $\gamma$-induced pro-inflammatory gene expression and cytokine secretion in human THP-1 monocytic cells (Roth, Spalinger, Müller, Lang, Rogler, \& Scharl, 2014). These findings suggested a crucial role for anthocyanins in modulating inflammatory responses. Billberry extract showed antihypoglycemic effect by inhibition the action of intestinal $\alpha$-glucosidase activity (Martineau et al., 2006). Takkikawa et al., (2010) investigated antidiabetic activities of billberry extract and found that dietary anthocyanin-rich bilberry extracts 
ameliorated hyperglycemia and insulin sensitivity in diabetic mice (Takikawa, Inoue, Horio, \& Tsuda, 2010). In another study Cignarella, et al., (1996) found that bilberry extract decreased levels of plasma glucose and triglycerides in streptozotocin (STZ)-induced diabetic mice (Cignarella, Nastasi, Cavalli, \& Puglisi, 1996).

\subsection{Cranberries}

\subsubsection{Source}

Cranberries (Vaccinium macrocarpon Ait.) also known as lowbush cranberries are native to USA belongs to Ericaceae family. USA is the world leader of cranberry producer with $90 \%$ of world production. Cranberries are consumed as fresh fruits, dried, jams, and juices. The US per capita consumption of cranberries is raising continuously mostly in the form of juices and remains at the top of healthy drinks.

\subsubsection{Composition}

Cranberries are rich source of various phytochemical compounds viz., flavan-3-ols, A type procyanidins (PACs), anthocyanins, benzoic acid, ursolic acid, and vitamin C (Table1). Among the PAC's comprising catechin, epicatchin, epigallocatechin cranberries have been known to have epicatechin as the major one. Although many fruits have proanthocyanidins but only cranberry have significant level of A type PAC. Recently Wang et al., (2020) investigated the analysis of cranberry proanthocyanidins using UPLC (Ultra Performance-ion mobility-high-resolution mass spectrometry and identified total of 304 individual A-type and B-type proanthocyanidins, including 40 trimers, 68 tetramers, 53 pentamers, 54 hexamers, 49 heptamers, 28 octamers, and 12 nonamers (Wang, Harrington, Chang, Wu, \& Chen, 2020). Anthocyanins in cranberries are composed of glycosides of the 6 aglycones with cyanidin, peonidin, malvidin, pelargonidin, delphinidin, and petunidin (Wu, $\&$ Prior, 2005). The major phenolic acid including hydroxycinnamic acids in cranberry are p-coumaric, sinapic, caffeic, and ferulic acids. Quercetin is the major flavonol compound present in cranberries. Ellagic acid with and without glucosides represent more than $50 \%$ of total phenolic compounds. However, level of phenolics and anthocyanins depends on the maturation stage of the cranberries.

\subsubsection{Health Benefits}

Cranberries have been used for several decades to prevent urinary tract infection. This health benefit is attributed to cranberries because proanthocyanidin can prevent adhering of Escherichia coli to uroepithelial cells in the urinary tract (Ermel, Georgeault, Inisan, Besnard, 2012). After consumption juice and various products of cranberries it was also believed to enhance the plasma antioxidant activities (Pedersen et al., 2000). In vitro study confirmed that cranberry extracts inhibited activities of angiotensin converting enzyme and thus it showed the potential in lowering blood pressure (Apostolidis, Kwon, \& Shetty, 2006). Cranberry also helped to reduce the cardiovascular disease risks and to protect against lipoprotein oxidation. Several studies confirmed that cranberries bioactive compounds have anti-cancer and antimutagenic activities (Prasain, Grubbs, \& Barnes, 2020; Howell, 2020). Recently Hsia et al., (2020) investigated that whether consumption of cranberry beverage would improve insulin sensitivity and other cardiovascular complications and reported that daily consumption for 8 weeks may not impact insulin sensitivity but could be helpful in lowering triglycerides and alters some oxidative stress biomarkers in obese individuals with a proinflammatory state (Hsia, Zhang, Beyl, Greenway, \& Khoo, 2020). Chew et al., (2019) reported the health benefits of cranberry beverage consumption on gluco regulation, oxidative damage, inflammation, and lipid metabolism in healthy overweight humans (Chew et al., 2019). Consumption of significant amount of cranberry beverage improved antioxidant status and reduced cardiovascular disease risk factors by improving glucoregulation, downregulating inflammatory biomarkers, and increasing HDL cholesterol.

\subsection{Viburnum Berries}

\subsubsection{Source}

Viburnum opulus L. (Adoxaceae), commonly known as European guelder, is also called as European cranberry bush, guelder rose, cherry-wood, and snowball bush. It grows in Europe, North and Central Asia, and North Africa. Viburnum is commonly used both in conventional and folk medicine in Russia. The State Pharmacopoeia of the Russian Federation (XI edition, issue 2) contains a monograph on the preparation of Viburnum fruits, and two medicinal drugs with Viburnum fruits are entered in the State Register of Medicinal Remedies of the Russian Federation. While parts of viburnum such as bark, flowers, and fruits are widely used in traditional medicine some fruits are used as cooking ingredients. In Russia, Ukraine, and among many Siberian nations the viburnum opulus (VO) fruits are used in traditional cuisine such as marmalades, jams, and "Kalinnikov" pies, and herbal teas. 
Viburnum opulus contain high level phenolic compounds such as hydroxybenzoic acids, tannins, flavonoids, anthocyanins, chlorogenic acid, catechin, epicatechin, cyanidin-3-glucoside, cyanidin-3-rutinoside and quercetin (Velioglu, Ekici, \& Poyrazoglu, 2006; Perova, I. B., Zhogova,Cherkashin,Éller, \&Ramenskaya, 2014).) (Table 1). In an investigation to profile phenolic compounds in viburnum berries using high-performance liquid chromatography Velioglu et al., (2006) identified chlorogenic acid (upto $2037 \mathrm{mg} / \mathrm{kg}$ ), catechin, epicatechin, cyanidin-3-glucoside, cyanidin-3-rutinoside and different glucosides of quercetin and cyanidin derivatives (Velioglu, Ekici, \& Poyrazoglu, 2006). Zakłos-Szyda (2019) has identified and quantified the major phenolic compounds where they reported chlorogenic acid as main component. Catechin was found to second most abundant phenolic compounds and Cyanidin 3-sambubioside was found to be major anthocyanin (Zakłos-Szyda, Majewska, Redzynia, \& Koziołkiewicz, 2019). In addition to these flavonol compounds quercetin-pentose, quercetin-hexose, quercetin-deoxyhexose and isorhamnetin glycosides, rutin and isorhamnetin were obtained. Çam et al. (2007) have showed that Viburnum Opulus seeds are also good source of total phenolics and flavonoids (Çam, Hisil, \& Kuscu, 2007).

\subsubsection{Health Benefits}

Viburnum opulum phenolic compounds impart various health beneficial properties. Number of in vitro studies reported high antioxidant activities by viburnum berries. Zakłos-Szyda et al, (2019) investigated the antioxidant activities of viburnum opulus and reported the strong correlation between total phenolics and radical scavenging activities such as ABTS and ORAC with high Pearson's correlation coefficients, $r=0.993$ and 0.991 respectively(Zakłos-Szyda, Majewska, Redzynia, \& Koziołkiewicz, 2019). Similar linear relationships between phenolics and antioxidants activities were observed by Karaçelik et al., (2015) in their study of identification of bioactive compounds of Viburnum opulus L. using on-line HPLC-UV-ABTS (High Performance Liquid Chromatography-Ultra violet- 2,2'-azinobis-(3-ethylbenzothiazoline-6-sulfonic acid) radical scavenging assay and LC-UV-ESI-MS (Liquid Chromatogrpahy-Ultra Violet Electro Spray Ionization Mass Spectrometry) (Karaçelik et al., 2015). Viburnum opulus extract also showed anticancer activities. In vitro studies using Caco-2 cell culture indicated that Viburnum opulus phenolic rich fraction prompted to decrease the uptake of free fatty acids and lower the accumulation of glucose and lipids by Caco-2 cells without affecting their viabilities (Zakłos-Szyda, Majewska, Redzynia, \& Koziołkiewicz, 2019). Moreover in vivo antitumoral activity of Viburnum opulus were confirmed by Ceylan et al., (2018) in Ehrlich ascites tumor model. Phenolic extract of Viburnum. opulus fruit also reported to be strong inhibitor of $\alpha$-amylase, $\alpha$-glucosidase, and/or PTP-1B phosphatase enzymes involved in lipid and carbohydrate metabolism (Zakłos-Szyda, Majewska, Redzynia, \& Koziołkiewicz, 2015).

\subsection{Cherries}

\subsubsection{Source}

Cherry is one of the major small fruits with bigger benefits belongs to family: Rosaceae and genus: Prunus. It is one of the major berries native to United States and is the second-largest producer in the world. The two major types of cherries are sweet cherries (Prunus avium) and tart or sour cherries (Prunus cerasus).

\subsubsection{Composition}

Sweet and sour cherries are distinguished from each other by their ratios of sugars (e.g., glucose, fructose, and others) to organic acids (mainly maleic acid). Cherries are rich source vitamins A, B, C, E, K, carotenoids, minerals, and phenolic compounds. Sour cherries have higher contents of vitamin A and betacarotene. Tart cherries contain significant levels of melatonin $(13.46 \pm 1.10 \mathrm{ng} / \mathrm{g}$ and $2.06 \pm 0.17 \mathrm{ng} / \mathrm{g}$ in Balaton and Montmorency, respectively) (Burkhardt, Tan, Manchester, Hardeland, \& Reiter, 2001). Chemical profiling of tart cherries indicated presence of cyanidin 3-glucoside, cyanidin 3-rutinoside, cyanidin 3-sophoroside, pelargonidin 3-glucoside, pelargonidin 3-rutinoside, peonidin 3-glucoside, and peonidin 3-rutinoside as important flavonoids (Kirakosyan, Seymour, Llanes, Daniel, Kaufman, \& Bolling, 2008) (Table 1). Among phenolic acids, hydroxycinnamates (neochlorogenic acid and p-coumaroylquinic acid) are reported to present in significant levels. Cherries also contain flavonols and flavan-3-ols such as catechin, epicatechin, quercetin 3-glucoside, quercetin 3-rutinoside, and kaempferol 3-rutinoside. Different cultivars of sweet and sour cherries have different levels of phenolics and flavonoids. For example, in a study Kim et al., (2005) studied different cultivars it was found that total anthocyanins of sweet cherries were 30 - $79 \mathrm{mg}$ cyanidin-3-glucoside equivalents (CGE)/100 g, whereas in sour cherries these were 45 - $109 \mathrm{mg}$ CGE/100g (Kim, Heo, Kim, Yang, \& Lee, 2005).

\subsubsection{Health Benefits}

Various studies demonstrated that tart cherries extract, and its compounds showed strong antioxidant activities 
(Blando, Gerardi, \& Nicoletti, 2004). Kirakosyan et al., (2008) reported the high TEAC (trolox equivalent antioxidant capacity) of two tart cherries viz Balaton and Montmorency and cyanidin and its derivatives were found to be the important antioxidants in the assays (Kirakosyan, Seymour, Llanes, Daniel, Kaufman, \& Bolling, 2008). Numerous studies indicated that cherry consumption inhibited inflammatory pathways. Consumption of cherries also helped to lower blood pressure, control blood glucose, protect against oxidative stress, and reduce inflammation (Martin, Burrel, \& Bopp, 2018; Martin, \& Coles, 2019). Kelley et al. (2006) showed that intake of sweet cherries decreased levels of C-reactive protein (CRP), a biomarker for inflammation and cardiovascular disease in healthy subjects (Kelley, Rasooly, Jacob, Kader, Mackey, 2006). In vitro and in vivo studies suggested that anti-inflammatory properties of polyphenolic compounds of cherries evidenced by the inhibition of activity of the cyclooxygenase II (COX II), another biomarkers for inflammation, carcinogenesis, cell proliferation, and angiogenesis (Wang, Nair, \& Strasburg,1999). Consumption of Cherry also showed to lower serum urate levels and inflammation (Martin, \& Coles, 2019). Zhang et al., (2012). reported that cherry consumption affected the risk of recurrent gout attacks (Zhang, Neogi, Chen, Chaisson, Hunter, \& Choi, 2012). Recently Lamb et al., (2020) also demonstrated the effect of tart cherry juice to reduce risk of recurrent gout flare (Lamb, Lynn, Russell, \& Barker, 2020). Di Bonaventura et al., (2020) indicated that tract cherry has potential role to prevent obesity-related risk factors, especially neuroinflammation based on a rat model study (Di Bonaventura et al., 2020). In a mice model study Smith et al., (2019) found that cherry supplementation (5\% and 10\%) improved bone mineral density (BMD) and some indices of trabecular and cortical bone microarchitecture and they proposed that these effects were likely attributed to increased bone mineralization (Smith et al., 2019).

\subsection{Sea Buckthorn Berries}

\subsubsection{Source}

Sea buckthorn, known as seaberry, (Elaeagnus rhamnoides L.) belongs to the family Elaeagnaceae. Even though sebuckthorn is cultivated mostly in Russia and China, now a days it is cultivated around other countries like Finland, Germany, and Estonia.

\subsubsection{Composition}

Sea buckthorn have been found to have a range of bioactive compounds including vitamin A, C, E, carotenoids, minerals, and polyphenols (Olas, 2016; Gradt, Kuhn, Morsel, \& Zvaigzne, 2017). A recent intensive analysis on composition of seabuckthorn berries indicated the presence of 21 phytochemicals such as isorhamnetin, quercetin, kaempferol glycosides and catechin. Phenolic compounds also include primarily proanthocyanidins, gallocatechins and flavonol glycosides (Dienaite, Pukalskas, Pukalskienè, Pereira, Matias, \& Venskutonis, 2020) (Table 1). Criste et al., (2020) also reported that seabuckthorn berries are great source of phenolic compounds such as derivatives of quercetin and hydrocinnamic acid. (Criste et al., 2020).

\subsubsection{Health Benefits}

Sea buckthorn exhibits a wide spectrum of pharmacological activities such as anti-inflammatory, anticancer, antioxidant, and anti-atherosclerotic activities (Zeb, 2006; Basu, Prasad, Jayamurthy, Pal, Arumughan, \& Sawhney, 2007; Olas, 2016). They also induce apoptosis and strengthen the immune system. In a study on the content and antioxidant activities of phenolic compounds of seabucthorn Gao et al., (2000) reported that antioxidant activities were strongly correlated with the content of total phenolic compounds and ascorbic acid (Gao, Ohlander, Jeppsson, Bjork, \& Trajkovski, 2000). It was also found that antioxidant activity of the lipophilic extract correlated with the total carotenoids content. A strong correlation existed between flavonoid content in seabuckthorn and their antioxidant activities $(r=0.96)$ (Criste et al., 2020). To investigate other health benefits recently Guo et al., (2020) reported that administration of freeze-dried seabuckthorn powder lowered body weight, Lee's index, adipose tissue weight, liver weight, and serum lipid levels induced by obesity (Guo, Han, Li, \& Yu, 2020). Tkacz et al., (2019) reported high in-vitro anti-oxidant and anti-enzymatic activities related to digestion system due to the presence of phytochemicals such as phenolic acids, flavonols, xanthophylls, carotenes, tocopherols, and tocotrienols( Tkacz, Wojdyło, Turkiewicz, Bobak, \& Nowicka, 2019). Number of studies reported that seabuckthorn oil exhibits anti-tumor properties due to the presence flavonoid compounds kaempferol, quercetin, and isorhamnetin (Christaki, 2012). Hao et al., (2019) found that seabuckthorn seed oil extracts were effective in reducing blood cholesterol in hypercholesterolemia hamsters (Hao et al., 2019).

\subsection{Raspberries}

\subsubsection{Source}

Raspberries, a popular soft fruit grown in Eastern Europe belongs to the family Rosaceae and genus Rubus. It is cultivated all over the world mainly in Europe (European red raspberry), North America (American variety), and 
Asia. In the early of $19^{\text {th }}$ century raspberries were grown in the United State of America. Now it is the third highest producer of raspberries. Black raspberries are also grown commercially in America. Purple raspberries are the hybrid of red and black raspberries. There are approximately 250 species of Rubus genera fruits however red raspberry (Rubus idaeus L.), the North American red raspberry (R. idaeus), and the black raspberry (Rubus occidentalis $L$.) are the most important commercial varieties (Wu, et al., 2019).

\subsubsection{Composition}

Raspberries are considered as healthy superfruits due to their rich source of vitamins C, A, B, B1, B2, E, folic acid, polyphenols, anthocyanins, and minerals. Raspberry as fruits are rich sources of polyphenols such as flavonoids, phenolic acids, ellagitannins, and ellagic acid. Among anthocyanins the major components in red raspberries ( $R$. idaeus) are cyanidin 3-sophoroside, cyanidin 3-glucosylrutinoside, cyanidin 3-glucoside and cyanidin 3-rutinoside (Table 1). Black raspberries (Rubus occidentalis) have cyanidin 3-sambubioside, cyanidin 3-rutinoside, and cyanidin 3-xylosylrutinoside. Ellagitannins and their derivative ellagic acid are other important hydrolysable tannins bioactive compounds that are available in fruit pulp and seeds of raspberries. Other biologically active phenolic compounds are quercetin-3- glucuronide and kaempferol-3-glucuronide, flavan-3-ols (catechin), and phenolic and hydroxy acids (gallic, salicyl, caffeic, p-hydroxybenoic, ferulic, p-cumaric, cinnamic and vanillic acids (Määttä-Riihinen, Kamal-Eldin, \& Törrönen, 2004; Tian, Giusti, Stoner, \& Schwartz, 2006; Mazur, Nes, Wold, Remberg,\& Aaby, 2014)).

\subsubsection{Health Benefits}

Raspberries confers significant antioxidant activities because of their polyphenolic compounds. (Lee, Dossett, \& Finn, 2012; Chen, Xin, Zhang, \& Yuan, 2013). Raspberries have been known to use traditional drug such as antipyretic and diaphoretic drug. It has been used in managing diabetes and hypertension, and inflammation (Liu,Schwimer, Liu, Greenway,Anthony, \& Woltering, 2005; Cheplick, Kwon, Bhowmik, \& Shetty, 2007; Medda et al., 2015 ). Polyphenol compounds of raspberries exerted antiproliferative activities against cervical and colon cancer cells (McDougall, Ross, Ikeji, \& Stewart, 2008). The raspberries extract also showed anti-proliferative activities against colon, prostate, breast, and oral cancer cells. (Wedge et al., 2001; Seeram et al., 2006; Ross, McDougall, \& Steward, 2007; Peiffer, 2018). Raspberry phenolics exhibited antimicrobial and antiviral activities. A growing evidence was found that berries could modify the composition of the gut microbiota (May, McDermott, Marchesi \& Perry, 2020). Recently Tu et al., (2020) investigated that administration of a diet rich in black raspberry changed the composition and diverse functional pathways in the mouse gut microbiome which suggested important role of the gut microbiome in the health effects of black raspberry extract (Tu et al., 2020).

\subsection{Acai Berries}

\subsubsection{Source}

Açaí a palm fruit, belongs to family Arecaceae and genus Euterpe. They are native to South America and grows significantly in the Amazon River delta in Brazil. Two primary species of açaí fruit that are popular are Euterpe precatoria (EP) and Euterpe oleracea (EO).They are highly consumed by the native people in that region but it has gained international reputation because of their potential nutrition and health benefits. The use of açá berries by native people to treat malaria related symptoms such as fever, pain, inflammation, and anemia has been seen long time. In the US marketplace commercial products containing açai fruit have been increasing rapidly during recent years (Lee, 2019).

\subsubsection{Composition}

Açaí fruit is a great source of polyphenolic compounds such as anthocyanins and phenolic acids (Yamaguchi, Pereira, Lamarão, Lima, \& Da Veiga-Junior, 2015) (Table 1). However, there were significant differences in the levels of these phytochemicals between the species such as Euterpe precatoria (EP) and Euterpe oleracea (EO). EP reported to have higher level of polyphenolic compounds compared to EO (Xie et al, 012). The major derivatives of anthocyanins in these berries are cyanidin-3-glucoside and cyanidin-3-rutinoside. In a study by Poulose et al., (2014) reported the level of anthocyanin content in the EP and EO extracts were very significant such as 2035 -66 ng/mg; cyanidin 3-glucoside, 18434 - $575 \mathrm{ng} / \mathrm{mg}$; cyanidin 3-rutinoside, 113 - $220 \mathrm{ng} / \mathrm{mg}$; delphinidin-glucoside, 538 - $27 \mathrm{ng} / \mathrm{mg}$, for malvidin-glucoside, 84 -8 ng/mg; pelargonidin-glucoside, and 371 $65 \mathrm{ng} / \mathrm{mg}$ for peonidin glucoside. Other phenolic compounds such as catechins, ferulic acid, quercetin, resveratrol, and vanillic acid were also greatly varied between the two species.

\subsubsection{Health Benefits}

Due to the presence of various polyphenolic composition, acại berries exhibit important health benefits. Various 
cell and animal model studies indicated that açaí extracts showed antioxidant, anti-inflammatory, anti-atherosclerotic, anti-aging, analgesic, and neuromodulatory properties.

Through antioxidant and anti-inflammatory activities acai berry extracts reduced the risk of atherosclerosis (Mertens-Talcott et al., 2008). Moreover, Xie et al. (2012) proposed that anti-inflammatory activities were attributed to the flavone velutin (Xie, et al., 2012). In-vivo and in-vitro cell and animal model study confirmed that extracts of acai fruits reduce oxidative stress and neuroinflammation via inhibition of activities and expression of nitrous oxide synthase (iNOS), cyclooxygenase-2 (COX-2), p38 mitogen-activated protein kinase (p38- MAPK), tumor necrosis factor- $\alpha$ (TNF- $\alpha$ ), and nuclear factor $\kappa B$ (NF- $\kappa B$ ) (Poulose et al., 2012). Extract of açaí fruit pulp specially from EO protected from neurotoxicity induced by lipopolysaccharide in mouse brain (Noratto, Angel-morales, Talcott, \& Mertenstalcott, 2011; Poulose et al., 2012). In addition to the in vivo and in vitro antioxidant and anticancer activities it was reported that Açaí juice from EO exhibited neuroprotective, anticonvulsant, and anti-seizure properties (Souza-Monteiro et al., 2015). Ferriera, et al., (2019) investigated potential use of acại polyphenols as novel antimalarial compounds in vitro and in vivo and indicated its potential effects of proteostasis as major molecular target (Ferriera, et al., 2019). Magalhães et al., (2020) demonstrated the protective effect of açaí pulp components on intestinal damage in 5-fluorouracil-induced Mucositis, as well as the ability to control the response to oxidative stress, in order to mobilize defense pathways and promote tissue repair (Magalhães et al., 2020). Recently de Liz et al., (2020) evaluated the effects of moderate-term açaí juice intake on fasting glucose, lipid profile, and oxidative stress biomarkers in healthy subject by assigning $200 \mathrm{~mL} /$ day for four weeks and collected blood before and after consumption. They found that there were increased the concentrations of HDLC (high- density lipoprotein cholesterol) by 7.7\%, TAC (total antioxidant capacity) by $66.7 \%$, antioxidant enzyme activities catalase by $275.1 \%$, and glutatathone peroxidase activity by $15.3 \%$ (de Liz et al., 2020).

\subsection{Maqui Berries}

\subsubsection{Source}

Maqui berry (Aristotelia chilensis), belongs to the family Elaeocarpaceae. This purple berry is native to Chile (Aristotelia chilensis) is one of the emerging Chilean superfruit with high nutraceutical value. It is consumed as fresh and dried fruits or also used to make tea, jam, cakes, drink, juice, alcoholic beverages.

\subsubsection{Composition}

Maqui berry are one of the richest sources of polyphenol compounds. The total phenol content of maqui berry is reported to be much higher than even superfruits blue berries $\left(97 \mu \mathrm{mol} \mathrm{GAE} \mathrm{g}{ }^{-1} \mathrm{FW}\right.$ and $17 \mu \mathrm{mol} \mathrm{GAE} \mathrm{g}{ }^{-1} \mathrm{FW}$ respectively) (Ruiz et al., 2010). Major phenolic compounds in Maqui berries are phenolic acids and flavonoids that includes flavonols, flavanols, and anthocyanins (Table 1). Among polyphenols maqui berries have highest level of anthocyanins. The major anthocyanins are 3-glucosides, 3,5-diglucosides, 3-sambubiosides and 3-sambubioside-5-glucosides of cyanidin and delphinidin (delphinidin 3-sambubioside-5-glucoside). Other flavonoids compounds are quercetin and its derivatives such as dimethoxy-quercetin, quercetin-3-rutinoside, quercetin-3-galactoside, dimethoxy-quercetinand ellagic acid.

\subsubsection{Health Benefits}

Maqui berry is reported to exhibit high antioxidant activities. The ORAC values of maqui was found to be $37,174 \mu \mathrm{mol}$ Trolox per $100 \mathrm{~g}$ of dry weight which was much higher than in commercial berries such as raspberries, blueberries and blackberries cultivated in Chile (Speisky, López Alarcón, Gómez, Fuentes, \& Sandoval Acuña, 2012). Bastías-Montes (2020) et al., also recently showed that seed oil from Maqui berry and their tocols $(\alpha, \beta, \gamma, \delta$-tocopherols, tocotrienols, and $\beta$-sitosterol) promoted for clinical investigation due to their high antioxidative and antiobesity potential against DPPH, HORAC (Hydroxyl Radical Antioxidant Capacity), ORAC (Oxygen Radical Absorbance Capacity), FRAP (ferric reducing antioxidant power), Lipid-peroxidation (TBARS), $\alpha$-amylase, $\alpha$-glucosidase, and pancreatic lipase (Bastías-Montes et al., 2020). The purified delphinidin extract maqui berry helped in the generation of nitrogen oxide (NO) in endothelial cells, decreased platelet adhesion, and possessed anti-inflammatory effects. Miranda-Rottmann, et al., (2002) reported that maqui berry extracts could prevent the oxidation of low-density lipoproteins and protected the cultures of human endothelial cells (Miranda-Rottmann, Aspillaga, Pérez, Vasquez, Martinez, \& Leighton, 2002). Maqui berries are used as dietary management in patients with respiratory disorders as anthocyanin maqui extract could normalize $\mathrm{H}_{2} \mathrm{O}_{2}$ and IL-6 concentrations in exhaled breath condensates (EBC) by asymptomatic smokers (Vergara, Ávila, Escobar, Carrasco-Pozo,, Sánchez, \& Gotteland,2015). Recently Zhou et al., (2019) reported that ethyl acetate fraction from maqui berry crude extract was rich in phenols and exhibited strong antioxidant and anti-inflammatory activities. They suggested that there was a possible prevention of cognitive damage due to the 
antioxidant activity of the maqui berry (Zhou et al., 2019). In a study with male rat brain exposed to ozone and treatment with extract of Maqui berry it was found that maqui berry extracts improved memory and decreased oxidative stress (Bribiesca-Cruz, Moreno, García-Viguera, Gallardo, Segura-Uribe, Pinto-Almazán, \& Guerra-Araiza, 2019).

\subsection{Elderberries}

\subsubsection{Source}

Elderberry (Sambucus nigra) is one of the richest sources of anthocyanins and are used as great source for production of antioxidants, colorants, and bioactive compounds industrially. Traditionally they have been used as medicinal components and food ingredients in fruits, jams, and juices. They are also more frequently used in the manufacture of various types of liqueurs.

\subsubsection{Composition}

Nutritional composition analysis reported that elderberry is a good source of nutrients like protein, amino acids, dietary fibres, vitamin B, A, and C phytochemicals. Some elderberries have higher level of organic acid and lower level of sugars which is important to industrially processing foods. More significantly elderberry is one of the richest sources of bioactive compounds like flavonols, flavanols, phenolic acids, proanthocyanidins, and anthocyanins (Table 1). Elderberries have been reported to have high level of anthocyanins containing total anthocyanin levels upto $1816 \mathrm{mg} / 100 \mathrm{~g}$ FW. Major anthocyanins in elder berries are cyanidin-3-O-sambubioside-5-glucoside, cyanidin-3,5-diglucoside, cyanidin-3-O-sambubioside, yanidin-3-rutinoside, cyanidin-3-glucoside, cyanidin-3-sambubioside, pelargonidin 3-glucoside, pelargonidin 3 -sambubioside, and delfinidine-3-rutinoside. However, their levels vary with different cultivars. Some other anthocyanins are also present in trace amounts. Major flavonols in elderberries were derivatives of quercetin, kaempferol and isorhamnetin. In the quercetin group quercetin 3-rutinoside and quercetin 3-glucoside were found to be in significant level. Among phenolic acids chlorogenic, crypto-chlorogenic and neochlorogenic acids were identified as major while small amounts of ellagic acids were also available in elderberry fruits. Proanthocyaninidins with monomers, dimers, and trimers, and tetramars have been found in elderberries (Veberic, Jakopic, Stampar, \& Schmitzer, 2009; Mikulic-Petkovsek, et al., 2014; Sidor, \& Gramza-Michałowska, 2015; Młynarczyk, Walkowiak-Tomczak, \& Łysiak, 2018;).

\subsubsection{Health benefits}

Elderberry has been used as folk medicine for the treatment of common cold, fevers, allergies, and ailments. Several reports demonstrated that elderberries are associated with antioxidant, anti-inflammatory, antibacterial, antiviral, and inflammation properties and various health beneficial properties (Sidor \& Gramza-Michałowska, 2015; Porter \& Bode, 2017; Olejnik, et al., 2015). Antioxidant activities of elderberries and its extracts were confirmed by in vitro antiradical activity assays viz., DPPH, ABTS, hydroxyl, and peroxyl. However, the potency of antioxidant activities depended on the assay, method of extraction bioactive compounds as well as type of elderberry cultivars. In some studies, it showed a less activities than choke berries and black berries and whereas in some other studies it showed higher than other berries (Viskelis, Rubinskiene', Bobinaite', \& Dambrauskiene, 2010; Wu et al. (2004)). Wu et al. (2004) investigated ability of elderberry extract to scavenge the peroxyl radical (ROO•) in the ORAC assay and reported upto $5783 \mu \mathrm{mol} \mathrm{TE} / \mathrm{g}$ extract which was higher than the activity of other extract of berries in the respective assay (Wu, Gu, Prior, \& McKay,2004). In vivo studies showed that an enhanced plasma and serum antioxidant activity was observed after consumption of elderberry (Netzel et al. (2005).

Several studies indicated the antidiabetic properties of elderberry extract. Administration of elderberry extract to diabetic rats helped to maintain glycemic index and reduced the increase in glycemia (Badescu, Badulescu, Badescu, \& Ciocoiu, 2012). Bhattacharya et al., (2013) reported the possible role of elderberry in the prevention and treatment of diabetes via the increasing in the secretion of insulin (Bhattacharya et al., 2013). Ho et al., $(2017 \mathrm{a}, \mathrm{b})$ reported that elderberry extracts showed high stimulation of glucose uptake in human liver cells and human skeletal muscle cells and inhibitory effect towards carbohydrate hydrolyzing enzymes after treatment with elderberry extracts (Ho, Nguyen, Kase,Tadesse, Barsett, \& Wangensteen, 2017). In vivo studies with STZ-induced diabetic rat fed with high fat diet Salvador et al., (2017) found that polar extract of elderberry modulated glucose metabolism by correcting hyperglycemia and in other way the lipophilic extract lowered insulin secretion (Salvador et al., 2017). Elderberry extract reported to boost immune system (Badescu, Badulescu, Badescu, Ciocoiu, 2015). Anti-inflammatory properties by elderberry extracts were evident from the findings that elderberry stimulated the production of proinflammatory cytokines IL-1 $\beta$, IL- 6 , IL- 8 and TNF- $\alpha$ (tumour necrosis factor) as well as anti-inflammatory cytokine IL-10 (Barak, Birkenfeld, Halperin, \& Kalickman, 
2002). Several studies indicated elderberry extract for antimicrobial and antiviral activity against human pathogenic bacteria as well as influenza viruses (Krawitz, Mraheil, Stein, Imirzalioglu, Domann, Pleschka, \&Hain, 2011). Elderberry flower extract inhibited the influenza A virus (H1N1)-induced Madin-Darby canine kidney (MDCK) cell infection (Roschek, Fink, McMichael, Li, \& Alberte, 2009). Recently it was reported that Sambucus Formosana Nakai stem ethanol extract displayed strong anti-HCoV-NL63 related to respiratory tract illnesses including runny nose, cough, bronchiolitis, and pneumonia (Weng et al. 2019). A significant study demonstrated the anticancer properties of elderberries including European and American elderberry fruits which demonstrated chemopreventive potential through strong induction of quinone reductase and inhibition of cyclooxygenase-2 (Thole et al, 2007).

\section{Conclusion}

A wide spectrum of in vitro and in vivo, and human studies has proven the berries antioxidant status and potential health benefits including cardiovascular, neuroprotective, anticarcinogenic potential, and antidiabetic properties. However, the bioavailability of polyphenolic compounds appears to be different with their structure, composition, and diet sources. Abundancy of polyphenols may not correlate strongly with the bioavailability. A thorough knowledge of the bioavailability of the series of polyphenolic compounds will help in promoting healthy choices for maximum health benefits. Further studies in profiling bioavailability and medicinal value are needed for potential application.

\section{References}

Aaby, K., Mazur, S., Nes, A., \& Skrede, G. (2012). Phenolic compounds in strawberry (Fragaria x ananassa Duch.) fruits: Composition in 27 cultivars and changes during ripening. Food Chemistry, 132, 86-97. https://doi.org/1016/j.foodchem.2011.10.037

Aaby, K., Skrede, G., \& Wrolstad, R. E. (2005). Phenolic composition and antioxidant activities in flesh and achenes of strawberries (Fragaria ananassa). Journal of Agricultural and Food Chemistry, 53, 4032-4040, https://doi.org/10.1021/jf048001o

Adams, L. S., Phung, S., Yee, N., Seeram, N. P., Li, L., \& Chen, S. (2010). Blueberry phytochemicals inhibit growth and metastatic potential of MDA-MB-231 breast cancer cells through modulation of the phosphatidylinositol 3-kinase pathway. Cancer Research, 70, 3594-3605. https://doi.org/10.1158/0008-5472.CAN-09-3565.

Agarwal, P., Holland, T. M., Wang, Y., Bennett, D. A. M., \& Morris, C. (2019). Association of strawberries and anthocyanidin intake with Alzheimer's Dementia Risk. Nutrients, 11, 3060. https://doi.org/10.3390/nu11123060

Akimov, M. U., Zhbanova, E. V., Makarov, V. N., Perova, I. B., Shevyakova, L. V., .. Mironov, A. M. (2019). Nutrient value of fruit in promising strawberry varieties. Vopr Pitan, 88(2), 64-72. https://doi.org/10.24411/0042-8833-2019-10019

Álvarez-Fernández, M. A., Hornedo-Ortega, R., Cerezo, A. B., Troncoso, A. M., \& García-Parrilla, M. C. (2014). Effects of the strawberry (Fragaria ananassa) purée elaboration process on non-anthocyanin phenolic composition and antioxidant activity. Food Chemistry, 164, 104-112. https://doi.org/10.1016/j.foodchem.2014.04.116

Al-Awwadi, N. A., Araiz, C., Bornet, A., Delbosc, S., Cristol, J. P., Linck, N., Azay, J., Teissedre, P.-L., \& Cros, G. (2005). Extracts enriched in different polyphenolic families normalize increased cardiac NADPH oxidase expression while having differential effects on insulin resistance, hypertension, and cardiac hypertrophy in highfructose-fed rats. Journal of Agricultural and Food Chemistry, 53, 151-157. https://doi.org/10.1021/jf048919f

Apostolidis, E., Kwon, Y. I., \& Shetty, K. (2006). Potential of cranberry-based herbal synergies for diabetes and hypertension management. Asian Pacific Journal of Clinical Nutrition, 15, 433-41.

Arevstrom, L., Bergh, C., Landberg, R., Wu, H. X., Rodriguez-Mateos, A., Waldenborg, M., Magnuson, A., Blanc, S., \& Frobert, O. (2019). Freeze-dried bilberry (Vaccinium myrtillus) dietary supplement improves walking distance and lipids after myocardial infarction: An open-label randomized clinical trial. Nutrition Research, 62, 13-22. https://doi.org/10.1016/j.nutres.2018.11.008

Barak, V., Birkenfeld, S., Halperin, T., \& Kalickman, I. (2002). The effect of herbal remedies on the production of human inflammatory and anti-inflammatory cytokines. The Israel Medical Association Journal, 4, 919-922. 
Badescu, L., Badulescu, O., Badescu, M., \& Ciocoiu, M. (2012). Mechanism by Sambucus nigra extract improves bone mineral density in experimental diabetes. Evidence-Based Complementary and Alternative Medicine, Article ID 848269. http://dx.doi.org/10.1155/2012/848269

Badescu, M., Badulescu, O., Badescu, L., \& Ciocoiu, M. (2015). Effects of Sambucus nigra and Aronia melanocarpa extracts on immune system disorders within diabetes mellitus. Pharmaceutical Biology, 53, 533-539. https://doi.org/10.3109/13880209.2014.931441

Basu, A., Morris, S., Nguyen, A., Betts, N. M., Fu, D., \& Lyons, T. J. (2016). Effects of dietary strawberry supplementation on antioxidant biomarkers in obese adults with above optimal serum lipids. Journal of Nutrition and Metabolism, 3910630. https://doi.org/10.1155/2016/3910630

Basu, A., Du, M., Leyva, M. J., Sanchez, K., Betts, N. M., Wu, M., Aston, C. E., \& Lyons, T. J. (2010). Blueberries decrease cardiovascular risk factors in obese men and women with metabolic syndrome. Journal of Nutrition, 140, 1582-1587. https://doi.org/10.3945/jn.110.124701

Basu, M., Prasad, R., Jayamurthy, P., Pal, K., Arumughan, C., \& Sawhney, R. C. (2007). Anti-atherogenic effects of seabuckthorn (Hippophaea rhamnoides) seed oil. Phytomedicine, 14, 770-777. https://doi.org/10.1016/j.phymed.2007.03.018

Bastías-Montes, J. M., Monterrosa, K., Muñoz-Fariña, O., García, O., Acuña-Nelson, S. M., ... Cespedes-Acuña, C. L. (2020). Chemoprotective and antiobesity effects of tocols from seed oil of Maqui-berry: Their antioxidative and digestive enzyme inhibition potential. Food Chemistry and Toxicology, 136, 111036. https://doi.org/10.1016/j.fct.2019.111036

Bhattacharya, S., Christensen, K. B., Olsen, L. C. B., Christensen,L. P., Grevsen, K., ... Oksbjerg, N. (2013). Bioactive components from flowers of Sambucus nigra L. increase glucose uptake in primary porcine myotube cultures and reduce fat accumulation in Caenorhabditis elegans. Journal of Agricultural and Food Chemistry, 61, 11033-11040. https://doi.org/10.1021/jf402838a

Blando, F., G.erardi, C., \& Nicoletti, I. (2004). Sour cherry (Prunus cerasus L.) anthocyanins as ingredients for functional foods. Journal of Biomedicine and Biotechnology, 5, 253-258. https://doi.org/10.1155/S1110724304404136

Bravo, L. (1998). Polyphenols: Chemistry, dietary sources, metabolism, and nutritional significance. Nutrition Reviews, 56, 317-333. https://doi.org/10.1111/j.1753-4887.1998.tb01670.x

Bribiesca-Cruz, I., Moreno, D. A., García-Viguera, C., Gallardo, J. M., Segura-Uribe, J. J., Pinto-Almazán, R., \& Guerra-Araiza, C. (2019). Maqui berry (Aristotelia chilensis) extract improves memory and decreases oxidative stress in male rat brain exposed to ozone. Nutritional Neuroscience, 1-13. https://doi.org/10.1080/1028415X.2019.1645438

Burkhardt, S., Tan, D. X., Manchester, L. C., Hardeland, R., \& Reiter, R. J. (2001). Detection and quantification of the antioxidant melatonin in Montmorency and Balaton tart cherries (Prunuscerasus). Journal of Agricultural and Food Chemistry, 49, 4898-4902. https://doi.org/10.1021/jf010321

Calò, R., \& Marabini, L. (2014). Protective effect of Vaccinium myrtillus extract against UVA- and UVB-induced damage in a human keratinocyte cell line (HaCaT cells). Journal of Photochemistry and Photobiology B: Biology, 132, 27-35. https://doi.org/10.1016/j.jphotobiol.2014.01.013

Çam, M., Hisil, Y., \& Kuscu, A. (2007). Organic acid, phenolic content, and antioxidant capacity of fruit flesh and seed of Viburnum opulus. Chemistry of Natural Compounds, 43, 460-461. https://doi.org/10.1007/s10600-007-0161-7

Carvalho, A. V., Ferreira da Silveira, T., Mattietto, R. A., Padilha de Oliveira, M. D., \& Godoy, H. T. (2017). Chemical composition and antioxidant capacity of açai (Euterpe oleracea) genotypes and commercial pulps. Journal of the Science, Food and Agriculture, 97, 1467-1474. https://doi.org/10.1002/jsfa.7886

Casto, B. C., Knobloch, T. J., Galioto, R. L., Yu, Z., Accurso, B. T., \& Warner, B. M. (2013). Chemoprevention of oral cancer by lyophilized strawberries. Anticancer Research, 33, 4757-4766.

Ceylan, D., Aksoy, A., Ertekin, T., Yay, A. H., Nisari, M., Karatoprak, G. Ş., Ülger, H. (2018). The effects of gilaburu (Viburnum opulus) juice on experimentally induced Ehrlich ascites tumor in mice. Journal of Cancer Research and Therapeutics, 14, 314-320. https://doi.org/10.4103/0973-1482.181173

Chew, B., Mathison, B., Kimble, L., McKay, D., Kaspar, K., Khoo, C., Chen, C. O., \& Blumberg, J. (2019). Chronic consumption of a low calorie, high polyphenol cranberry beverage attenuates inflammation and 
improves glucoregulation and HDL cholesterol in healthy overweight humans: a randomized controlled trial, European Journal of Nutrition, 58, 1223-1235. https://doi.org/10.1007/s00394-018-1643-z

Chen, L., Xin, X., Zhang, H., \& Yuan, Q. (2013). Phytochemical properties and antioxidant capacities of commercial raspberry varieties, Journal of Functional Foods, 5, 508-515. https://doi.org/10.1016/j.jff.2012.10.009

Christaki, E. (2012). Hippophae rhamnoides L. (Sea Buckthorn): a potential source of nutraceuticals. Food and Public Health, 2, 69-72. https://doi.org/10.5923/j.fph.20120203.02

Cheplick, S., Kwon, Y., Bhowmik, P., \& Shetty, K. (2007). Clonal variation in raspberry fruit phenolics and relevance for diabetes and hypertension management. Journal of Food Biochemistry, 31, 656-679. https://doi.org/10.1111/j.1745-4514.2007.00136.x

Cho, M. J., Howard, L. R., Prior, R. L., \& Clark, J. R. (2004). Flavonoid glycosides and antioxidant capacity of various blackberry, blueberry and red grape genotypes determined by high-performance liquid chromatography/mass spectrometry. Journal of the Science of Food and Agriculture, 84, 1771-1782. https://doi.org/10.1002/jsfa.1885

Cianciosi, D., Simal-Gándara, J., \& Forbes-Hernández, T. Y. (2019). The importance of berries in the human diet. Mediterranean Journal of Nutrition and Metabolism, 12(4), 335-340, https://doi.org/10.3233/MNM-190366

Cignarella, A., Nastasi, M., Cavalli, E., \& Puglisi, L. (1996). Novel lipid-lowering properties of Vaccinium myrtillus L. leaves, a traditional antidiabetic treatment, in several models of rat dyslipidaemia: A comparison with ciprofibrate. Thrombosis Research, 84, 311-322. https://doi.org/10.1016/s0049-3848(96)00195-8

Criste, A., Urcan, A. C., Bunea, A., Pripon, Furtuna, F. R., Olah, N. K., Madden, R. H., \& Corcionivoschi, N. (2020). Phytochemical composition and biological activity of berries and leaves from four Romanian sea buckthorn (Hippophae Rhamnoides L.) varieties. Molecules, 5, E1170. https://doi.org/10.3390/molecules25051170

Dienaite, L., Pukalskas, A., Pukalskienė, M., Pereira, C. V., Matias, A. A., \& Venskutonis, P. R. (2020). Phytochemical composition, antioxidant and antiproliferative activities of defatted sea buckthorn (Hippophaë rhamnoides L.) berry pomace fractions consecutively recovered by pressurized ethanol and water. Antioxidants (Basel), 9, E274. https://doi.org/10.3390/antiox9040274

Di Bonaventura, M. M. V., Martinelli, I., Moruzzi, M., Di Bonaventura, M. E., Giusepponi, M. E., ... Tomassoni, D. (2020). Brain alterations in high fat diet induced obesity: effects of tart cherry seeds and juice. Nutrients, 27(12), 623. https://doi.org/10.3390/nu12030623

Del Bo', C., Riso, P., Campolo, J., Møller, P., Loft, S., Klimis-Zacas, D., Brambilla, A., Rizzolo, A., \& Porrini, M. (2013). A single portion of blueberry (Vaccinium corymbosum L.) improves protection against DNA damage but not vascular function in healthy male volunteers. Nutrition Research, 33, 220-227. https://doi.org/10.1016/j.nutres.2012.12.009

Earling, M., Beadle, T., \& Niemeyer, E. D. (2019). Açai Berry (Euterpe oleracea) Dietary Supplements: Variations in Anthocyanin and Flavonoid Concentrations, Phenolic Contents, and Antioxidant Properties. Plant Foods and Human Nutrition, 74, 421-429. https://doi.org/10.1007/s11130-019-00755-5

Ermel, G., Georgeault, S., Inisan, C., \& Besnard, M. (2012). Inhibition of adhesion of uropathogenic Escherichia coli bacteria to uroepithelial cells by extracts from cranberry. Journal of Medicinal Food, 15, 126-134. https://doi.org/10.1089/jmf.2010.0312

Eken, A., Yücel, O., İpek, İ., Ayşe, B., \& Endİrlïk, B. Ü. (2017). An investigation on protective effect of Viburnum opulus L. fruit extract against ischemia/reperfusion-induced oxidative stress after lung transplantation in rats. Kafkas Üniversitesi Veteriner Fakültesi Dergisi., 23, 437-444.

Ferreira, L. T., Venancio, V. P., Kawano, T., Abrão, L. C. C., Tavella, T. A., Almeida, L. D., ... Costa, F. T. M., (2019). Chemical genomic profiling unveils the in vitro and in vivo antiplasmodial mechanism of Açaí (Euterpe oleracea Mart.) polyphenols. ACS Omega, 4, 15628-15635. https://doi.org/10.1021/acsomega.9b02127

Fierascu, R. C., Temocico, G., Fierascu, I., Ortan, A. \& Babeanu, N. E. (2020). Fragaria Genus: chemical composition and biological activities, Molecules, 25, 498. https://doi.org/10.3390/molecules25030498 
Forbes-Hernández, T. Y. (2020). Berries polyphenols: Nano-delivery systems to improve their potential in cancer therapy. Journal of Berry Research, 10(1), 45-60. https://doi.org/10.3233/JBR-200547

Gao, X., Ohlander, M., Jeppsson, N., Bjork, L., \& Trajkovski, V. (2000). Changesin antioxidant effects and their relationship to phytonutrients in fruits of seabuckthorn (Hippophae rhamnoides L.) during maturation, Journal of Agricultural and Food Chemistry, 48, 1485-1490. https://doi.org/10.1021/jf991072g

Giampieri, F., Tulipani, S., Alvarez-Suarez, J. M., Quiles, J. L., Mezzetti, B., \& Battino M. (2012). The strawberry: Composition, nutritional quality, and impact on human health, Nutrition, 28, 9-19. https://doi.org/10.1016/j.nut.2011.08.009

Gradt, I., Kuhn, S., Morsel, J., \& Zvaigzne, G. (2017). Chemical composition of sea buckthorn leaves, branches, and bark. Proceedings of Natural Academy of Science U.S.A., 3, 211-216. https://doi.org/10.1515/prolas-2017-0035

Gu, L., Kelm, M. A., Hammerstone, J. F., Beecher, G., Holden, J., Haytowitz, D., Gebhardt, S., \& Prior, R. L. (2004). Concentrations of proanthocyanidins in common foods and estimations of normal consumption. Journal of Nutrition, 134, 613-614, https://doi.org/10.1093/jn/134.3.613

Guo, C., Han, L., Li, M., \& Yu, L. (2020). Seabuckthorn (Hippophaë rhamnoides) freeze-dried powder protects against high-fat diet-induced obesity, lipid metabolism disorders by modulating the gut microbiota of mice. Nutrients, 2, E265. https://doi.org/10.3390/nu12010265

Hao, W., He, Z., Zhu, H., Liu, J., Kwek, E., Zhao, Y., Ma, K. Y., He, W. S., Chen, Z. Y. (2019). Sea buckthorn seed oil reduces blood cholesterol and modulates gut microbiota, Food \& Function, 10, 5669-5681. https://doi.org/10.1039/c9fo01232j

Halvorsen, B. L., Carlsen, M. H., Phillips, K. M., Holte, K., Jacobs, D. R., \& Blomhoff, R. (2006) Content of redox active compounds (ie, antioxidnats) in foods consumed in the United States. American Journal of Nutrition, 84, 95-135. https://doi.org/10.1093/ajcn/84.1.95

Heinonen, M., Meyer, A. S., \& Frankel, E. N. (1998). Antioxidant activity of berry phenolics on human low-density lipoprotein and liposome oxidation. Journal of Agricultural and Food Chemistry, 46, 4107-4111. https://doi.org/10.1021/jf980181c

Hsia, D. S., Zhang, D. J., Beyl, R. S., Greenway, F. L., \& Khoo, C. (2020). Effect of daily consumption of cranberry beverage on insulin sensitivity and modification of cardiovascular risk factors in obese adults: a pilot randomized placebo-controlled study. British Journal of Nutrition, 1-27. https://doi.org/10.1017/S0007114520001336

Hwang, H., Kim, Y. J., \& Shin, Y. (2019). Influence of ripening stage and cultivar on physicochemical properties, sugar and organic acid profiles, and antioxidant compositions of strawberries. Food Science and Biotechnology, 28(6), 1659-1667. https://doi.org/10.1007/s10068-019-00610-y

Ho, G. T. T., Nguyen, T. K. Y., Kase, E. T., Tadesse, M., Barsett, H., \& Wangensteen H. (2017, a). Enhanced glucose uptake in human liver cells and inhibition of carbohydrate hydrolyzing enzymes by nordic berry extracts. Molecules, 22, 1806. https://doi.org/10.3390/molecules22101806

Ho, G. T. T., Kase, E. T., Wangensteen, H., \& Barsett, H. (2017, b). Phenolic elderberry extracts, anthocyanins, procyanidins, and metabolites influence glucose and fatty acid uptake in human skeletal muscle cells. Journal of Agricultural and Food Chemistry, 65, 2677-2685. https://doi.org/10.1021/acs.jafc.6b05582

Howell, A. B. (2020). Potential of cranberry for suppressing Helicobacter pylori, a risk factor for gastric cancer. Journal of Berry Research, 10, 11-20. https://doi.org/10.3233/JBR-180375

Jielong, G., Xue, H., Hongyu, T., Weidong, H., Yilin, Y., \& Jicheng, Z. (2019). Blueberry extract improves obesity through regulation of the gut microbiota and bile acids via pathways involving FXR and TGR5. iScience, 19, 676-690. https://doi.org/10.1016/j.isci.2019.08.020

Kähkönen, M. P., Hopia, A. I., \& Heinonen, M. (2001). Berry phenolics and their antioxidant activity. Journal of Agricultural and Food Chemistry, 49, 4076-82. https://doi.org/10.1021/jf010152t

Kalemba-Drożdż, M., Cierniak, A., \& Cichoń, I., (2020). Berry fruit juices protect lymphocytes against DNA damage and ROS formation induced with heterocyclic aromatic amine PhIP. Journal of Berry Research, 10(1), 95-1130. https://doi.org/10.3233/JBR-190429

Kalt, W., Forney, C. F., Martin, A., \& Prior, R. L. (1999). Antioxidant capacity, vitamin C, phenolics, and anthocyanins after fresh storage of small fruits. Journal of Agricultural and Food Chemistry, 47, 4638-4644. 
https://doi.org/10.1021/jf990266t

Kalt, W., Ryan, D. A. J., Duy, J. C., Prior, R. L., Ehlenfeldt, M. K., \& Vander Kloet, S. P. (2001). Interspecific variation in anthocyanins, phenolics, and antioxidant capacity among genotypes of highbush and lowbush blueberries (Vaccinium section cyanococcus spp.). Journal of Agricultural and Food Chemistry, 49, 4761-4767. https://doi.org/10.1021/jf010653e

Kalt, W., \& McDonald, J. E. (1996). Chemical composition of lowbush blueberry cultivars. Journal of American Society of Horticultural Sciences, 121, 142-146. https://doi.org/10.21273/JASHS.121.1.142

Karlsen, A., Paur, I., Bohn, S. K., Sakhi, A. K., Borge, G. I., Serafini, M., Erlund, I., Laake, P., Tonstad, S., \& Blomhoff, R. (2010). Bilberry juice modulates plasma concentration of NF-kappa B related inflammatory markers in subjects at increased risk of CVD. European Journal of Nutrition, 49, 345-355. https://doi.org/10.1007/s00394-010-0092-0

Karlsen, A., Retterstol, L., Laake, P., Paur, I., Kjolsrud-Bohn, S., Sandvik, L., \& Blomhoff, R. (2007). Anthocyanins inhibit nuclear factor-kappa B activation in monocytes and reduce plasma concentrations of pro-inflammatory mediators in healthy adults. Journal of Nutrition, 137, 1951-1954. https://doi.org/10.1093/jn/137.8.1951

Karaçelik, A. A., Küçük, M., İskefiyeli, Z., Aydemir, S., De Smet, S., Miserez, B., \& Sandra, P., (2015). Antioxidant components of Viburnum opulus L. determined by on-line HPLC-UV-ABTS radical scavenging and LC-UV-ESI-MS methods. Food Chemistry, 175, 106-14. https://doi.org/10.1016/j.foodchem.2014.11.085

Kelley, D. S., Rasooly, R., Jacob, R. A., Kader, A. A., \& Mackey, B. E. (2006). Consumption of Bing sweet cherries lowers circulating concentrations of inflammation markers in healthy men and women. Journal of Nutrition, 136, 981-986. https://doi.org/10.1093/jn/136.4.981

Kim, D., Heo, H. J., Kim, Y. J., Yang, H. S., \& Lee, C. Y. (2005). Sweet and Sour Cherry Phenolics and Their Protective Effects on Neuronal Cells. Journal of Agricultural and Food Chemistry, 53, 9921-9927, https://doi.org/10.1021/jf0518599

Kirakosyan, A., Seymour, E. M., Llanes, U., Daniel, E., Kaufman, P. B., \& Bolling, S. F. (2008). Chemical profile and antioxidant capacities of tart cherry products. Food Chemistry, 115. https://doi.org/10.1016/j.foodchem.2008.11.042

Kolehmainen, M., Mykkanen, O., Kirjavainen, P. V., Leppanen, T., Moilanen, E., Adriaens, M., ... Pulkkinen, L. (2012). Bilberries reduce low-grade inflammation in individuals with features of metabolic syndrome. Molecular Nutrition and Food Research, 56, 1501-1510. https://doi.org/10.1002/mnfr.201200195

Kristo, A. S., Klimis-Zacas, D., \& Sikalidis, A. K. (2016). Protective role of dietary berries in cancer. Antioxidants, 5, 37. https://doi.org/10.3390/antiox5040037

Krawitz, C., Mraheil, M. A., Stein, M., Imirzalioglu, C., Domann, E., Pleschka, S., \& Hain, T. (2011). Inhibitory activity of a standardized elderberryliquid extract against clinically-relevant human respiratory bacterial pathogens and influenza A and B Viruses. BMC Complement Alternative Medicine, 11, 16. https://doi.org/10.1186/1472-6882-11-16

Lamb, K. L., Lynn, A., Russell, J., \& Barker, M. E. (2020). Effect of tart cherry juice on risk of gout attacks: protocol for a randomised controlled trial. BMJ Open, 10, e035108.

https://doi.org/10.1136/bmjopen-2019-035108

Lee, J., Dossett, M., \& Finn, C. E. (2012). Rubus fruit phenolics research: The good, the bad, and the confusing. Food Chemistry, 130, 785-796. https://doi.org/10.1016/j.foodchem.2011.08.022

Lee, J. (2019). Anthocyanins of açai products in the United States. NFS Journal, 14-15, 14-21. https://doi.org/10.1016/j.nfs.2019.05.001

Liu, J., Zhang, W., Jing, H., \& Popovich, D. G. (2010). Bog bilberry (Vaccinium uliginosum L.) extract reduces cultured Hep-G2, Caco-2, and 3T3-L1 cell viability, affects cell cycle progression, and has variable effects on membrane permeability. Journal of Food Science 75, 103-107.

https://doi.org/10.1111/j.1750-3841.2010.01546.x

Liu, Z., Schwimer, J., Liu, D., Greenway, F. L., Anthony, C. T., \& Woltering, E. A. (2005). Black raspberry extract and fractions containing angiogenesis inhibitors. Journal of Agricultural and Food Chemistry, 53, 3909-3915. https://doi.org/10.1021/jf048585u 
de Liz, S., Cardoso, A. L., Copetti, C. L. K., Hinnig, P. F., Vieira, F. G. K., .. Di Pietro, P. F. (2020). Açaí (Euterpe oleracea Mart.) and juçara (Euterpe edulis Mart.) juices improved HDL-c levels and antioxidant defense of healthy adults in a 4-week randomized cross-over study. Clinical Nutrition. https://doi.org/10.1016/j.clnu.2020.04.007

Lopes-da-Silva, F., de Pascual-Teresa, S., Rivas-Gonzalo, J. C., \& Santuos-Buelga, C. (2002). Identification of anthocyanin pigments in strawberry (cv. Camarosa) by LC using DAD and ESI-MS detection. European Food Research and Technology, 214, 248-253. https://doi.org/10.1007/s00217-001-0434-5

Määttä-Riihinen, K. R., Kamal-Eldin, A., \& Törrönen, A. R. (2004). Identification and quantification of phenolic compounds in berries of Fragaria and Rubus species (Family Rosaceae). Journal of Agricultural and Food Chemistry, 52, 6178-6187. https://doi.org/10.1021/jf049450r

Magalhães, T. A. F. M., Souza, M. O., Gomes, S. V., Mendes, E. Silva, R., Martins, F. D. S., Freitas, R. N., \& Amaral, J. F. D. (2020). Açaí (Euterpe oleracea Martius) promotes jejunal tissue regeneration by enhancing antioxidant response in 5-Fluorouracil-Induced Mucositis. Nutrition and Cancer, 1-11. https://doi.org/10.1080/01635581.2020.1759659

Marniemi, J., Hakala, P., Maki, J., \& Ahotupa, M. (2000). Partial resistance of low density lipoprotein to oxidation in vivo after increased intake of berries. Nutrition, Metabolism, and Carbiovascular Diseases, 10, 331-337. https://doi.org/10.1016/j.phymed.2006.08.005

Martin, K. R., \& Coles, K. M. (2019). Consumption of $100 \%$ tart cherry juice reduces serum urate in overweight and obese adults. Current Developments in Nutrition, 3, 1-9. https://doi.org/10.1093/cdn/nzz011

Martin, K. R., Burrel, L., \& Bopp, J. (2018). Authentic tart cherry juice reduces markers of inflammation in overweight and obese subjects: a randomized, crossover pilot study. Food \& Function, 9, 5290-5300. https://doi.org/10.1039/c8fo01492b

Martinelli, E. M., Baj, A., \& Bombardelli, E. (1986). Computer-aided evaluation of liquid-chromatographic profiles for anthocyanins in Vaccinium myrtillus fruits. Analytica Chimica Acta, 191, 275-281. https://doi.org/10.1016/S0003-2670(00)86314-X

Martineau, L. C., Couture, A., Spoor, D., Benhaddou-Andaloussi, A., Harris, C., ... Haddad, P. S. (2006). Anti-diabetic properties of the Canadian lowbush blueberry Vaccinium angustifolium Ait. Phytomedicine, 13, 612-623. https://doi.org/10.1016/j.phymed.2006.08.005

Méndez-Lagunas, L., Rodríguez-Ramírez, J., Cruz-Gracida, M., Sandoval-Torres, S., \& Barriada-Bernal, G. (2017). Convective drying kinetics of strawberry (Fragaria ananassa): Effects on antioxidant activity, anthocyanins and total phenolic content. Food Chemistry, 230, 174-181. shttps://doi.org/10.1016/j.foodchem.2017.03.010

Martineau, L. C., Couture, A., Spoor, D., Benhaddou-Andaloussi, A., Harris, C., ... Haddad, P. S. (2006). Anti-diabetic properties of the Canadian lowbush blueberry Vaccinium angustifolium Aiton. Phytomedicine, 13, 612-623. https://doi.org/10.1016/j.phymed.2006.08.005

May, S., McDermott, G., Marchesi, J. R., \& Parry, L. (2020). Impact of black raspberries on the normal and malignant Apc deficient murine gut microbiome. Journal of Berry Research, 10(1), 61-76. https://doi.org/10.3233/JBR-180372

Mazur, S. P., Nes, A., Wold, A. B., Remberg, S. F., \& Aaby, K. (2014). Quality and chemical composition of ten red raspberry (Rubus idaeus L.) genotypes during three harvest seasons. Food Chemistry, 160, 233-240. https://doi.org/10.1016/j.foodchem.2014.02.174

McAnulty, L. S., Collier, S. R., Pike, J., Thompson, K. L., \& McAnulty, S. R. (2019). Time course of blueberry ingestion on measures of arterial stiffness and blood pressure. Journal of Berry Research, 9, 631-640. https://doi.org/10.3233/JBR-190413

McDougall, G. J., Ross, H. A., Ikeji, M., \& Stewart, D. (2008). Berry extracts exert different antiproliferative effects against cervical and colon cancer cells grown in vitro. Journal of Agricultural and Food Chemistry, 56, 3016-3023. https://doi.org/10.1021/jf073469n

Medda, R., Lyros, O., Schmidt, J. L., Jovanovic, N., Nie, L., ... Rafiee, P. (2015). Anti-inflammatory and anti-angiogenic effect of black raspberry extract on human esophageal and intestinal microvascular endothelial cells. Microvascular Research, 97, 167-180. https://doi.org/10.1016/j.mvr.2014.10.008

Mertens-Talcott, S. U., Rios, J., Jilma-Stohlawetz, P., PachecoPalencia, L. A., Meibohm, B., Talcott, S. T., \& 
Derendorf, H. (2008). Pharmacokinetics of anthocyanins and antioxidant effects after the consumption of anthocyanin-rich Açai juice and pulp (Euterpe oleracea Mart.) in human healthy volunteers. Journal of Agricultural Food Chemistry, 56, 7796-7802. https://doi.org/10.1021/jf8007037

Miranda-Rottmann, S., Aspillaga, A. A., Pérez, D. D., Vasquez, L., Martinez, A. L. F., \& Leighton, F. (2002). Juice and phenolic fractions of the berry Aristotelia chilensis inhibit LDL oxidation in vitro and protect human endothelial cells against oxidative stress. Journal of Agricultural and Food Chemistry, 50, 7542-7547. https://doi.org/10.1021/jf025797n

Mikulic-Petkovsek, M., Schmitzer, V., Slatnar, A., Todorovic, B., Veberic, R., Stampar, F., \& Ivancic, A. (2014). Investigation of anthocyanin profile of four elderberry species and interspecific hybrids. Journal of Agricultural and Food Chemistry, 62, 5573-5580. https://doi.org/10.1021/jf5011947

Młynarczyk, K., Walkowiak-Tomczak, D., \& Łysiak, G. P. (2018). Bioactive properties of Sambucus nigra L. as a functional ingredient for food and pharmaceutical industry. Journal of Functional Foods, 40, 377-390. https://doi.org/10.1016/j.jff.2017.11.025

Netzel, M., Strass, G., Herbst, M., Dietrich, H., Bitsch, R., Bitsch, I., \& Frank, T. (2005). The excretion and biological antioxidant activity of elderberry antioxidants in healthy humans. Food Research International, 38, 905-910. https://doi.org/10.1016/j.foodres.2005.03.010

Nile, S. H., \& Park, S. W. (2014). Edible berries: bioactive components and their effect on human health. Nutrition, 30, 134-144. https://doi.org/10.1016/j.nut.2013.04.007

Noratto, G. D., Angel-morales, G., Talcott, S. T., \& Mertenstalcott, S. U. (2011). Polyphenolics from acai,'(Euterpe oleracea Mart.) and red muscadine grape (Vitis Rotundifolia) protect human umbilical vascular endothelial cells (HUVEC) from glucose- and lipopolysaccharide (LPS)-induced inflammation and target microRNA-126. Journal of Agricultural Food Chemistry, 59, 7999-8012. https://doi.org/10.1021/jf201056x

Nowicka, A., Kucharska, A. Z., Sokół-Ł ‘ etowska, A., \& Fecka, I. (2019). Comparison of polyphenol content and antioxidant capacity of strawberry fruit from 90 cultivars of Fragaria $\times$ ananassa Duch. Food Chemistry, 270, 32-46. https://doi.org/10.3390/foods8120682

Olas, B. (2016). Sea buckthorn as a source of important bioactive compounds in cardiovascular diseases. Food Chemistry and Toxicology, 97, 199-204. https://doi.org/10.1016/j.fct.2016.09.008

Olejnik, A., Kowalska, K., Olkowicz, M., Rychlik, J., Juzwa, W., Myszka, K., Dembczy 'nski, R., \& Białas, W. (2015). Anti-inflammatory effects of gastrointestinal digested Sambucus nigra L. fruit extract analysed in co-cultured intestinal epithelial cells and lipopolysaccharide-stimulated macrophages. Journal of Functional Foods, 19, 649-660. https://doi.org/10.1016/j.jff.2015.09.064

Pan, P., Huang, Y. W., Oshima, K., Yearsley, M., Zhang, J., Yu, J., Arnold M., \& Wanga L. S. (2018). An immunological perspective for preventing cancer with berries. Journal of Berry Research, 8, 163-175, https://doi.org/10.3233/JBR-180305

Pan, P., Skaer, C., Yu J., Hui, Z., Ren, H., Oshima, K., \& Wang, L. S. (2017). Berries and other natural products in pancreatic cancer chemoprevention in human clinical trials. Journal of Berry Research, 7, 147-161. https://doi.org/10.3233/JBR-170159

Park, S. J., Shin, W.H., Seo, J. W., \& Kim, E. J. (2007). Anthocyanins inhibit airway inflammation and hyperresponsiveness in a murine asthma model. Food Chemistry and Toxicology, 45, 1459-1467. https://doi.org/10.1016/j.fct.2007.02.013

Pedersen, C. B., Kyle, J., McE Jenkinson, A., Gardner, P. T., McPhail, D. B., \& Duthie, G. G. (2000). Effects of blueberry and cranberry juice consumption on the plasma antioxidant capacity of healthy female volunteers. European Journal of Clinical Nutrition, 54, 405-408. https://doi.org/10.1038/sj.ejcn.1600972

Peiffer, D. S. (2018). Preparing black raspberry components for their use as cancer therapeutics. Journal of Berry Research, 8, 297-306. https://doi.org/10.3233/JBR-180364

Perova, I. B., Zhogova, A. A., Cherkashin, A. V., Éller, K. I., \& Ramenskaya, G. V. (2014). Biologically active substances from European Guelder berry fruits. Pharmaceutical Chemistry Journal, 48, 332-339. https://doi.org/10.1007/s11094-014-1105-8

Phaniendra, A., Jestadi, D. B., \& Periyasamy, L. (2015). Free Radicals: properties, sources, targets, and their implication in various diseases. Indian Journal of Clinical Biochemistry, 30, 11-26. 
https://doi.org/10.1007/s12291-014-0446-0

Piberger, H., Oehme, A., Hofmann, C., Dreiseitel, A., Sand, P. G., Obermeier, F. Schoelmerich, J., Schreier, P., Krammer, G., \& Rogler, G. (2011). Bilberries and their anthocyanins ameliorate experimental colitis. Molecular Nutrition and Food Research, 55, 1724-1729. https://doi.org/10.1002/mnfr.201100380

Porter, R. S., \& Bode R. F. (2017). A Review of the antiviral properties of black elder (Sambucus nigra L.) Products. Phytotherapy Research, 31, 533-554. https://doi.org/10.1002/ptr.5782

Poulose, S. M., Fisher, D. R., Larson, J., Bielinski, D. F., Rimando, A. M., Carey, A. N., Schauss, A. G., \& Shukitt-Hale, B. (2012). Anthocyanin-rich açai (Euterpe oleracea Mart.) fruit pulp fractions attenuate inflammatory stress signaling in mouse brain BV-2 microglial cells. Journal of Agricultural and Food Chemistry, 60, 1084-93. https://doi.org/10.1021/jf203989k

Poulose, S. M., Fisher, D. R., Bielinski, D. F., Gomes, S. M., Rimando, A. M., Schauss, A. G., \& Shukitt-Hale, B. (2014). Restoration of stressor-induced calcium dysregulation and autophagy inhibition by polyphenol-rich açaí (Euterpe spp.) fruit pulp extracts in rodent brain cells in vitro. Nutrition, 30, 853-862. https://doi.org/10.1016/j.nut.2013.11.011

Prasain, J. K., Grubbs, C., \& Barnes, S. (2020). Cranberry anti-cancer compounds and their uptake and metabolism: An updated review. Journal of Berry Research, 10, 1-10. https://doi.org/10.3233/JBR-180370

Prymont, P. A., Zwolinska, A., Sarniak, A., Wlodarczyk, A., Krol, M., Nowak, M., ... Nowak, D. (2014). Consumption of strawberries on a daily basis increases the non-urate 2,2-diphenyl-1-picryl-hydrazyl (DPPH) radical scavenging activity of fasting plasma in healthy subjects. Journal of Clinical Biochemistry and Nutrition, 55, 48-55. https://doi.org/10.3164/jcbn.13-93

Puupponen-Pimiä, R., Nohynek, L., Meier, C., Kähkonen, M., Heinonen, M., Hopia, A., \& Oksman-Caldentey, K. M. (2001) Antimicrobial properties of phenolic compounds from berries. Journal of Applied Microbiology, 90, 494-507. https://doi.org/10.1046/j.1365-2672.2001.01271.x

Reboredo-Rodr'iguez, P. (2018). Potential roles of berries in the prevention of breast cancer progression. Journal of Berry Research, 8, 307-323. https://doi.org/10.3233/JBR-180366

Rodriguez-Mateos, A., Cifuentes-Gomez, T., Tabatabaee, S., Lecras, C., \& Spencer, J. P. (2012). Procyanidin, anthocyanin, and chlorogenic acid contents of highbush and lowbush blueberries. Journal of Agricultural and Food Chemistry, 60, 5772-5778. https://doi.org/10.1021/jf203812w

Rodríguez-Daza, M. C., Daoust, L., Boutkrabt, L., Pilon, G., Varin, T., Dudonné, S., Levy, É., Marette, A., Roy, D., \& Desjardins, Y. (2020). Wild blueberry proanthocyanidins shape distinct gut microbiota profile and influence glucose homeostasis and intestinal phenotypes in high-fat high-sucrose fed mice. Scientific Reports, 10, 2217. https://doi.org/10.1038/s41598-020-58863-1

Roschek, B., Jr., Fink, C. R., McMichael, M. D., Li, D., \& Alberte, R. S. (2009). Elderberry flavonoids bind to and prevent H1N1 infection in vitro. Phytochemistry, 70, 1255-1261.

https://doi.org/10.1016/j.phytochem.2009.06.003

Ross, H. A., McDougall, G. J., \& Steward, D. (2007). Antiproliferative activity is predominantly associated with ellagitannins in raspberry extracts. Phytochemistry, 68, 218-228.

https://doi.org/10.1016/j.phytochem.2006.10.014

Rothwell, J. A., Perez-Jimenez, J., Neveu, V., Medina-Remón, A., M'hiri, N., ... Scalbert, A. (2013). Phenol-Explorer 3.0: a major update of the Phenol-Explorer database to incorporate data on the effects of food processing on polyphenol content. Database (Oxford). 7, bat070.

https://doi.org/10.1093/database/bat070

Roth, S., Spalinger, M. R., Müller, I., Lang, S., Rogler, G., \& Scharl, M. (2014). Bilberry-derived anthocyanins prevent IFN- $\gamma$-induced pro-inflammatory signalling and cytokine secretion in human THP-1 monocytic cells. Digestion, 90, 179-189. https://doi.org/10.1159/000366055

Routray, W., \& Orsat, V. (2011). Blueberries and their anthocyanins: factors affecting biosynthesis and properties. Comprehensive Reviews in food Science and Food Safety. https://doi.org/10.1111/j.1541-4337.2011.00164.x

Ruiz, A., Hermosín, I., Mardones, C., Vergara, C., Herlitz, C., Vega, M., Dorau, C., Winterhalter P., \& Von Baer D. (2010). Polyphenols and antioxidant activity of calafate (Berberis microphylla) fruits and other native berries from southern Chile. Journal of Agricultural and Food Chemistry, 58, 6081-6089.

https://doi.org/10.1021/jf100173x 
Salvador, Â. C., Król, E., Lemos, V. C., Santos, S. A. O., Bento, F. P. M. S., ... Krejpcio, Z. (2017). Effect of Elderberry (Sambucus nigra L.) extract supplementation in STZ-induced diabetic rats fed with a high-fat diet. International Journal of Molecular Science, 18, 13. https://doi.org/10.3390/ijms18010013

Schantz, M., Mohn, C., Baum, M., \& Richling, E. (2010). Antioxidative efficiency of an anthocyanin rich bilberry extract in the human colon tumor cell lines Caco-2 and HT-29. Journal of Berry Research, 1, 25-33. https://doi.org/10.3233/BR-2010-003

Schell, J., Scofield, R. H., Barrett, J. R., Kurien, B. T., Betts, N., Lyons, T. J., Zhao, Y. D., \& Basu, A. (2017). Strawberries improve pain and inflammation in obese adults with radiographic evidence of knee osteoarthritis. Nutrients, 9, 949. https://doi.org/10.3390/nu9090949

Schauss, A. G., Wu, X., Prior, R. L., Ou, B., Patel, D., Huang, D., \& Kababick, J. P. (2006). Phytochemical and nutrient composition of the freeze-dried amazonian palm berry, Euterpe oleraceae Mart. (Acai). Journal of Agricultural and Food Chemistry, 54, 8598-8603. https://doi.org/10.1021/jf060976g

Scibisz, I., \& Mitek, M. (2007). Influence of freezing process and frozen storage on anthocyanin contents of highbush blueberries. Food Science and Technology Qual., 5, 231-238.

Seeram, N. P., Adams, L. S., Zhang, Y., Lee, R., Sand, D., Scheuller, H. S., \& Heber, D. (2006). Blackberry, black raspberry, blueberry, cranberry, red raspberry, and strawberry extracts inhibit growth and stimulate apoptosis of human cancer cells in vitro. Journal of agricultural and Food Chemistry, 54, 9329-9339. https://doi.org/10.1021/jf061750g

Sidor, A., \& Gramza-Michałowska, A. (2015). Advanced research on the antioxidant and health benefit of elderberry (Sambucus nigra) in food-A review. Journal of Functional Foods, 18, 941-958. https://doi.org/10.1016/j.jff.2014.07.012

Smith, B. J., Crockett, E. K., Chongwatpol, P., Graef, J. L., Clarke, S. L., Rendina-Ruedy, E., \& Lucas, E. A. (2019). Montmorency tart cherry protects against age-related bone loss in female C57BL/6 mice and demonstrates some anabolic effects. European Journal of Nutrition, 58, 3035-3046. https://doi.org/10.1007/s00394-018-1848-1

Speisky, H., López Alarcón, C., Gómez, M., Fuentes J., \& Sandoval, A. C. (2012). First web-based database on total phenolics and oxygen radical absorbance capacity (ORAC) of fruits produced and consumed within the South Andes Region of South America. Journal of Agricultural and Food Chemistry, 60, 8851-8859. https://doi.org/10.1021/jf205167k

Souza-Monteiro, J. R., Hamoy, M., Santana-Coelho, D., Arrifano, G. P., Paraense, R. S., ... Crespo-López, M. E. (2015). Anticonvulsant properties of Euterpe oleracea in mice. Neurochemistry International, 90, 20-27. https://doi.org/10.1016/j.neuint.2015.06.014

Stote, K. S., Wilson, M. M., Hallenbeck, D., Thomas, K., Rourke, J. M., Sweeney, M. I., Gottschall-Pass, K. T., \& Gosmanov A. R. (2020). Effect of Blueberry Consumption on Cardiometabolic Health Parameters in Men with Type 2 Diabetes: An 8-Week, Double-Blind, Randomized, Placebo-Controlled Trial. Current Development in Nutrition, 4, 030. https://doi.org/10.1093/cdn/nzaa030

Stull, A. J., Cash, K. C., Johnson, W. D., Champagne, C. M., \& Cefalu, W. T. (2010). Bioactives in blueberries improve insulin sensitivity in obese, insulin-resistant men and women. Journal of Nutrition, 140, 1764-1768. https://doi.org/10.3945/jn.110.125336

Sun, Y. (1990). Free radicals, antioxidant enzymes, and carcinogenesis. Free Radical Biology and Meicice, 8, 583-599. https://doi.org/10.1016/0891-5849(90)90156-D

Taiz, L., \& Zeiger, E. (2006). Plant physiology. 4th ed. Sinauer Associates, Sunderland, Massachusetts. pp. 316-344 and 672-705. Computer-aided evaluation of liquidchromatographic profiles for anthocyanins in Vaccinium myrtillus fruits. Analytica Chimica Acta, 191, 275-281. https://doi.org/10.1016/S0003-2670(00)86314-X

Takikawa, M., Inoue, S., Horio, F., \& Tsuda, T. (2010). Dietary anthocyanin-rich bilberry extract ameliorates hyperglycemia and insulin sensitivity via activation of AMP-activated protein kinase in diabetic mice. Journal of Nutrition, 140, 527-533, https://doi.org/10.3945/jn.109.118216

Thole, J. M., Kraft, B. T. F., Sueiro, L. A., Kang, Y., Gills J., J., Cuendet, M., Pezzuto, J. M., Seigler, D. S., \& Lila, M. A. (2007). A comparative evaluation of the anticancer properties of European and American elderberry fruits. Journal of Medicinal Foods, 9, https://doi.org/10.1089/jmf.2006.9.498 
Tian, J. L., Liao, X. J., Wang, Y. H., Si, X., Shu, C., Gong, E. S., Xie, X., Ran, X. L., \& Li, B. (2019). Identification of cyanidin-3-arabinoside extracted from blueberry as a selective Protein Tyrosine Phosphatase 1B inhibitor. Journal of Agricultural and Food Chemistry, 67, 13624-13634. https://doi.org/10.1021/acs.jafc.9b06155

Tian, Q., Giusti, M. M., Stoner, G. D., \& Schwartz, S. J., (2006). Characterization of a new anthocyanin in black raspberries (Rubus occidentalis) by liquid chromatography electrospray ionization tandem mass spectrometry. Food Chemistry, 94, 465-468. https://doi.org/10.1016/j.foodchem.2005.01.020s

Tkacz, K., Wojdyło, A., Turkiewicz, I. P., Bobak, Ł., \& Nowicka, P. (2019). Anti-oxidant and anti-enzymatic activities of sea buckthorn (Hippophaë rhamnoides L.) fruits modulated by chemical components. Antioxidants (Basel), 8, E618. https://doi.org/10.3390/antiox8120618

Triebel, S., Trieu, H. L., \& Richling, E. (2012). Modulation of inflammatory gene expression by a bilberry (Vaccinium myrtillus L.) extract and single anthocyanins considering their limited stability under cell culture conditions. Journal of Agricultural and Food Chemistry, 60, 8902-8910. https://doi.org/10.1021/jf3028842

Tu, P., Bian, X., Chi, L., Xue, J., Gao, B., Lai, Y., Ru, H., \& Lu, K. (2020). Metabolite profiling of the gut microbiome in mice with dietary administration of black raspberries. ACS Omega, 5, 1318-1325, https://doi.org/10.1021/acsomega.9b00237

Türck, P., Fraga, S., Salvador, I., Campos-Carraro, C., Lacerda, D., ... da Rosa A. S. (2020). Blueberry extract decreases oxidative stress and improves functional parameters in lungs from rats with pulmonary arterial hypertension, Nutrition, 70, 110579. https://doi.org/10.1016/j.nut.2019.110579s

Uttara, B., Singh, A. V., Zamboni, P., \& Mahajan, R. T. (2009). Oxidative stress and neurodegenerative diseases: A review of upstream and downstream antioxidant therapeutic options. Current Neuropharmacology, 7, 65-74. https://doi.org/10.2174/157015909787602823

Valko M., Leibfritz, D., Jan, M., Cronin, M. T. D., Mazur, M., \& Telser, J. (2007). Free radicals and antioxidants in normal physiological functions and human disease. International Journal of Biochemistry and Cell Biology, 39, 44-84. https://doi.org/10.1016/j.biocel.2006.07.001

Veberic, R., Jakopic, J., Stampar, F., \& Schmitzer, V. (2009). European elderberry (Sambucus nigra L.) rich in sugars, organic acids, anthocyanins, and selected polyphenols. Food Chemistry, 114, 511-515. https://doi.org/10.1016/j.foodchem.2008.09.080

Vergara, D., Ávila, D., Escobar, E., Carrasco-Pozo, C., Sánchez, A., \& Gotteland, M. (2015). The intake of maqui (Aristotelia chilensis) berry extract normalizes $\mathrm{H} 2 \mathrm{O} 2$ and IL-6 concentrations in exhaled breath condensate from healthy smokers - an explorative study. Nutrition Journal, 14. https://doi.org/10.1186/s12937-015-0008-1

Velioglu, Y. S., Ekici, L., \& Poyrazoglu, E. S. (2006). Phenolic composition of European cranberrybush (Viburnum opulus L.) berries and astringency removal of its commercial juice. International Journal of Food Science and Technology, 41, 1011-1015. https://doi.org/10.1111/j.1365-2621.2006.01142.x

Viskelis, P., Rubinskiene', M., Bobinaite', R., \& Dambrauskiene', E. (2010). Bioactive compounds and antioxidant activity of small fruits in Lithuania. Journal of Food, Agriculture \& Environment, 8, 259-263.

Wang, S. Y., \& Lin, H. S. (2000). Antioxidant activity in fruits and leaves of blackberry, raspberry, and strawberry varies with cultivar and developmental stage. Journal of Agricultural and Food Chemistry, 48, 140-146. https://doi.org/10.1021/jf9908345

Wang, H., Nair, M. G., \& Strasburg, G. M. (1999). Antioxidant and antiinflammatory activities of anthocyanins and their aglycon, cyanidin, from tart cherries. Journal of Natural Product, 62, 294-296. https://doi.org/10.1021/np980501m

Wang, Y., de B Harrington, P., Chang, T., Wu, X., \& Chen, P., (2020). Analysis of cranberry proanthocyanidins using UPLC-ion mobility-high-resolution mass spectrometry, Analytical and Bioanalytical Chemistry. https://doi.org/10.1007/s00216-020-02601-z

Wedge, D. E., Meepagala, K. M., Magee, J. B., Smith, S. H., Huang, G., \& Larcom, L. L. (2001). Anticarcinogenic activity of strawberry, blueberry, and raspberry extracts to breast and cervical cancer cells. Journal of Medicinal Food, 4, 49-51. https://doi.org/10.1089/10966200152053703

Weng, J. R., Lin, C. S., Lai, H. C., Lin, Y. P., Wang, C. Y., Tsai, Y. C., Wu, K. C., Huang, S. H., \& Lin, C. W., 
(2019). Antiviral activity of Sambucus Formosana Nakai ethanol extract and related phenolic acid constituents against human coronavirus NL63. Virus Research, 273, 197767.

https://doi.org/10.1016/j.virusres.2019.197767

Wu, X., Sun, J., Ahuja, J., Haytowitz, D. B., Chen, P., Burton-Freeman, B., \& Pehrsson, P. R. (2019). Anthocyanins in processed red raspberries on the US market. Journal of Berry Research, 9, 603-613. https://doi.org/10.3233/JBR-190405

Wu, X., Gu, L., Prior, R. L., \& McKay, S. (2004). Characterization of anthocyanins and proanthocyanidins in some cultivars of Ribes, Aronia, and Sambucus and their antioxidant capacity. Journal of Agricultural and Food Chemistry, 52, 7846-7856. https://doi.org/10.1021/jf0486850

Wu, X., \& Prior, R. L. (2005). Systematic identification and characterization of anthocyanins by HPLC-ESI-MS/MS in common foods in the United States: fruits and berries. Journal of Agricultural and Food Chemistry, 53, 2589-99. https://doi.org/10.1021/jf048068b

Xie, C., Kang, J., Burris, R., Ferguson, M. E., Schauss, A. G., Nagarajan, S., \& Wu, X. (2011). Açaí juice attenuates atherosclerosis in ApoE deficient mice through antioxidant and anti-inflammatory activities. Atherosclerosis, 216, 327-333. https://doi.org/10.1016/j.atherosclerosis.2011.02.035

sXie, C., Kang, J., Li, Z., Schauss, A.G., Badger, T. M., Nagarajan, S., Wu, T., \&Wu, X. (2012). The açaí flavonoid velutin is a potent anti-inflammatory agent: Blockade of LPS-mediated TNF- $\alpha$ and IL-6 production through inhibiting NF- $\mathrm{BB}$ activation and MAPK pathway. Journal of Nutritional Biochemistry, 23, 1184-1191. https://doi.org/10.1016/j.jnutbio.2011.06.013

Yamaguchi, K. K. D. L., Pereira, L. F. R., Lamarão, C. V., Lima, E. S., \& Da Veiga-Junior, V. F. (2015). Amazon acai: Chemistry and biological activities: A review. Food Chemistry, 179, 137-151. https://doi.org/10.1016/j.foodchem.2015.01.055

Yeung, A. W. K., Tzvetkov, N. T., Zengin, G., Wang, D., Xu, S., ... Atanasov, A. G. (2019). The berries on the top. Journal of Berry Research, 9, 125-139. https://doi.org/10.3233/JBR-180357

Zakłos-Szyda, M., Pawlik, N., Polka, D., Nowak, A., Koziołkiewicz, M., \& Podsędek, A. (2019). Viburnum opulus fruit phenolic compounds as cytoprotective agents able to decrease free fatty acids and glucose uptake by Caco-2 cells. Antioxidants (Basel), 8, E262. https://doi.org/10.3390/antiox8080262

Zakłos-Szyda, M., Majewska, I., Redzynia, M., \& Koziołkiewicz, M. (2015). Antidiabetic effect of polyphenolic extracts from selected edible plants as $\alpha$-amylase, $\alpha$-glucosidase and PTP1B inhibitors, and $\beta$-pancreatic cells cytoprotective agents- a comparative study. Current Topics in Medicinal Chemistry, 15, 2431-2444. https://doi.org/10.2174/1568026615666150619143051

Zeb, A. (2006). Anticarcinogenic potential of lipids from hippophae -evidence from the recent literature. Asian Pacific Journal of Cancer Prevention, 7, 32-34.

Zhang, Y., Seeram, N. P., Lee, R., Feng, L., \& Heber, D. (2008). Isolation and identification of strawberry phenolics with antioxidant and human cancer cell antiproliferative properties. Journal of Agricultural and Food Chemistry, 56, 670-675. https://doi.org/10.1021/jf071989c

Zhang, Y., Neogi, T., Chen, C., Chaisson, C., Hunter, D. J., \& Choi, H. K. (2012). Cherry consumption and decreased risk of recurrent gout attacks. Arthritis \& Rheumatology, 64, 4004-11. https://doi.org/10.1002/art.34677

Zhou, G., Chen, L., Sun, Q., Mo, Q. G., Sun, W. C., \& Wang, Y. W. (2019). Maqui berry exhibited therapeutic effects against DSS-induced ulcerative colitis in C57BL/6 mice. Food and Function, 10, 6655-6665. https://doi.org/10.1039/c9fo00663j

\section{Copyrights}

Copyright for this article is retained by the author(s), with first publication rights granted to the journal.

This is an open-access article distributed under the terms and conditions of the Creative Commons Attribution license (http://creativecommons.org/licenses/by/4.0/). 